\title{
Sustainability and the 21st Century Vertical City: A Review of Design Approaches of Tall Buildings
}

\author{
Kheir Al-Kodmany \\ Department of Urban Planning and Policy, College of Urban Planning and Public Affairs, \\ University of Illinois at Chicago, Chicago, IL 60607, USA; kheir@uic.edu
}

Received: 19 June 2018; Accepted: 31 July 2018; Published: 3 August 2018

\begin{abstract}
As cities cope with rapid population growth—adding 2.5 billion dwellers by 2050 -and grapple with destructive sprawl, politicians, planners, and architects have become increasingly interested in the vertical city paradigm. Given the large-scale problems of skyscrapers, any improvements in their planning, design, and construction would be significant. This paper examines a new crop of skyscrapers that employs green design elements, including aerodynamic forms, greeneries, energy-saving systems, innovative renewable energy techniques, water-saving technologies, rainwater catchment systems, and the like. The examined projects illustrate foremost sustainable design features, strategies, and techniques that help to meet the functional requirements while resulting in attractive forms. They include towers that are completed, under-construction, on-hold, proposed and on the drawing boards. In an attempt to capture a wide-range of innovative ideas and concepts, this paper examines 30 major projects representing major world's regions that have been active in constructing tall buildings including Southeast Asia and the Far East, the Middle East, Europe, and North America. The discussion section also engages the reader with additional buildings that have employed similar sustainable design. The paper concludes by identifying design approaches that could twin sustainability with iconicity, and highlights some of the shortfalls of intended sustainable design.
\end{abstract}

Keywords: form; passive design; greeneries; function; energy; aesthetics; sustainable design

\section{Introduction}

\subsection{Sustainability}

The concept of sustainability continues to be of paramount importance to our cities [1,2]. Planners, architects, economists, environmentalists, and politicians persist in using the term in their conversations and writings. The term "sustainability" frequently appears in academic literature, professional conferences and organizations, and in practice. For example, the American Planning Association (APA) continues to use this term in its discussions, publication, and programs. The APA's Sustaining Places Initiative, a program that is dedicated to promoting sustainability in human settlements, has recently released several important reports that center on sustainability. Remarkably, among these reports is Sustaining Places: Best Practices for Comprehensive Plans (2015) by David R. Godschalk and David C. Rouse. The report offers planners and architects a detailed guide to creating comprehensive sustainable plans [3].

Similarly, the United Nations' World Urban Forum (WUF), which is the world's premier conference on urban issues, uses "sustainability" as a guiding theme to its myriad activities. Since its first meeting in Nairobi, Kenya in 2002, through the latest in Rio de Janeiro in 2016, the WUF uses the concept of "sustainability" as central to their agenda.

Importantly, WUF uses the term "sustainable" in each of its objectives, as follows [4]: 
- raise awareness of sustainable urbanization among stakeholders and constituencies, including the general public;

- improve the collective knowledge of sustainable urban development through inclusive, open debates, sharing of lessons learned and the exchange of best practices and commendable policies; and

- increase coordination and cooperation between different stakeholders and constituencies for the advancement and implementation of sustainable urbanization.

Sustainability is a broad concept. Its comprehensiveness is apparent in one of the earliest and most frequently used definitions that was created by the United Nations' Bruntland Commission in 1987. The commission defined sustainability as "meeting the needs of the present without compromising the ability of future generations to meet their own needs" [5]. Concisely, this definition resonates the root meaning of the word "sustain", which is to "provide with nourishment" or to "keep going", as defined by Merriam-Webster Dictionary [6]. Therefore, in line with the urban planning and architecture professions, sustainability emphasizes the long-term implications of all human activities. It also presumes that resources are finite and that we should use them conservatively and wisely according to long-term priorities and consequences of the ways we use them $[7,8]$. Notably, in his book The Architecture of Community, Léon Krier presents sustainable urbanism as "an ethical and civilizing vision of universal stature" ([9], p. 101).

Indeed, efforts to promote sustainability are growing throughout the world because people—including city officials, planners, architects, and community members-can more easily see the links between sustainability and other important planning paradigms, including "resilient", "ecological", "green" and "smart" design. For example, it is not enough to build sustainable communities. We must make them resilient so that they withstand natural disasters, economic recessions, or political malfeasance. In the same token, it is not only crucial to design and construct resiliently but to employ also smart technologies, green designs, and ecological principles $[10,11]$. Therefore, the centrality and comprehensiveness of sustainability suggest using it as an "umbrella" term that captures a wide-spectrum of practical projects under different agendas-"ecological", "sustainable", "green", "resilient" and "smart"-which all share the common thread of reducing harmful impact on the environment while delivering economically viable, healthy, and comfortable human habitats.

\subsection{Sustainability and Tall Buildings}

Sustainable, high-performance buildings and 'green architecture' have become important architectural criteria today as concerns about increased world population in conjunction with the depletion of natural resources, renewal and recycling of natural and synthetic materials, as well as construction of non-renewable energy resources, take on global proportions. Architects have been in a race to build the most sustainable buildings, and most recently, architects have an aggressive agenda to build the greenest skyscrapers. "The green meets the blue" expression refers to how architects are incorporating sustainable design principles augmented with new materials and technology into the design of tall buildings. Green building design principles also point to resource-efficient approaches to construct a tall building that will eventually be more economical to operate. Energy conservation in tall building design has become a determinant for the building's form, expression, exterior cladding systems, nature and extent of exterior glazing, and the size and location of atrium [12,13].

To be the greenest skyscraper in the city, designers are incorporating cutting-edge energy and water-saving technologies, like helical wind turbine technology, thousands of solar panels, sunlight-sensing LED lights, rainwater catchment systems, and even seawater-powered air conditioning. Recent green design demonstrates that energy-conserving measures can produce efficient tall buildings. For example, New York City's Hearst Tower is largely made from recycled steel and uses rainwater for $50 \%$ of its needs. The Pearl River Tower (also known as 'Zero-Energy' Skyscraper) in Guangzhou, China, by SOM (Skidmore, Owings \& Merrill) has semielliptical exterior 
and was designed to produce as much energy as it consumes. The 71-story tower uses wind, solar, and geothermal energy to power itself, and even the Empire State Building, one of the world's oldest skyscrapers, recently underwent an energy retrofit facelift to stay in the race. The 'bioclimatically designed' buildings—including T.R. Hamzah and Ken Yeang's Menara Mesiniaga/IBM Building of 1992 in Selangor, Malaysia-employ passive ventilation and "gardens in the air" [11]. Fox and Fowle's Four Times Square Building (also known as Conde Nast Building) of 1999 in New York City incorporates an array of photovoltaic cells on its facades and roof to supply energy needs. Burjal-Taqa 'Energy Tower', a 68-story proposed skyscraper with a 197-foot roof turbine and 161,459 square feet of solar panels, will create all of its own power. This is a growing trend in skyscraper design during the present energy-conscious era [14,15]. Notably, Commerzbank Tower is considered largely as the first ecological tower in Europe. Building upon the High-Tech and Green traditions of earlier decades, the tower creatively employs passive ecological strategies in conjunction with advanced technologies. The tower's rigorous integration of environmentally responsible technologies was a product of the unique political and economic climate of the 1990s when Frankfurt was governed by a coalition of Social Democrats and Green Party, who imposed a range of requirements to make tall buildings sustainable [16].

\subsection{Sustainability and Iconicity}

The term "iconic" often evokes controversy. In some design circles, iconic architecture has received harsh criticism for embracing inappropriate forms, including awkward, insensitive, inappropriate, cost intensive, and eccentric designs, for the mere purpose of competing for attention. According to Jeanne Gang, "The problem is that the highly visible position of the tall building in global culture has led to one-liners and symbolism in a superficial battle for identity" ([17], p. 1). They have often been associated with irrelevant, ostentatious design meant to gain popularity and attention.

Celebrated architects or "starchitects" have been criticized for producing edifices that do not fit the ecological and cultural contexts for which they were built and do not answer programmatic or functional needs. As Andree Iffrig has explained, the "iconic has become synonymous with wacky crowns on high-rise buildings that come down hard at grade, and are unusual architectural forms" ([18], p. 1). According to Iffrig, these buildings outrageously defy basic needs and functionalities. They have added more harm than good to the built environment, and are considered inimical. The term "iconic" was once used to identify outstanding architecture. Today, the term has fallen into disrepute. For some critics, "iconicity" has become a disparaging appellation.

However, green design is transforming the architecture of skyscrapers and producing new aesthetics that is based on eco-friendly design features and principles. In other words, the green design revolution has produced new aesthetical qualities, in some cases, iconic and strikingly unconventional. These iconic green skyscrapers enjoy local even global status and are considered to be among the most attractive. These tall buildings possess powerful imageability and embrace green design technologies simultaneously. These eco-iconic skyscrapers put their cities on the map by making their cities receive national and international recognition. Although modern skyscrapers tend to focus on employing green technologies to attain sustainable design, the paper reminds with the ecological work of Frank Lloyd Wright, specifically the Price Tower, which relied completely on passive green design measures [16].

\subsection{Goal of Study and Scope of Work}

The overarching purpose of this paper is to examine the effect of green design ideas on tall buildings. The specific goal is to investigate how green design ideas are influencing the resulting building's form. The long and sustained debate on form versus function relates to this research; and as such, the paper' findings may clarify some of the controversial issues on this topic. For that end, the paper attempts to answer the following inter-related questions:

- What are the common green design ideas that tall buildings have been incorporating recently?

- How green design features and approaches affect the resulting forms? 
- Does iconicity result from manipulating forms per se, or can it serve functional needs and purposes?

- Can genuine concepts and green design principles result in interesting and eye-catching tall buildings?

- How can tall buildings twin sustainability with innovative aesthetics?

The paper attempts to devise a conceptual framework for understanding new functional and architectural expressions. In examining over 30 towers, the paper maps out key and common green design features. It summarizes them and identifies important features that affect the resulting forms. The following examples illustrate a wide range of green design elements, strategies, and techniques. They include towers that were mainly constructed in the past two decades. Later, the paper in the discussion section engages additional tall buildings examples that have pursued green design, built and unbuilt. The examined case studies are presented in an order based on their continents: Southeast Asia and the Far East, Middle East, Europe, and North America.

\section{Southeast Asia and the Far East}

\subsection{Shanghai Tower}

Located in the Pudong Financial District of Shanghai, China, the 128-floor Shanghai Tower rises to a height of $632 \mathrm{~m}(2073 \mathrm{ft})$. When completed in 2015, it became the tallest building in China and second world's tallest, ranking that it retains to the present. As an exemplary mixed-use tower, it is divided into nine vertical zones with retail at the bottom, offices in the middle, and hotels, cultural facilities, and observation decks at the top. Designed by the architectural firm Gensler, the tower features numerous green design elements, including a tapering, twisting form that reduces wind loads by $24 \%$, offering significant savings in overall building materials. The building's transparent inner and outer skins admit maximum natural daylight, thereby reducing the need for electric light. The tower's outer skin also insulates the building, reducing energy use for heating and cooling. Further, the tower's spiral parapet collects rainwater, which is used for the tower's heating and air conditioning systems [16]. The Council on Tall Buildings and Urban Habitat (CTBUH) recognized Shanghai Tower as the "2016 Best Tall Building Worldwide" (Figure 1).

\subsection{Pearl River Tower}

Located in Guangzhou, China, the Pearl River Tower was designed by Adrian Smith and SOM. Rising to $309 \mathrm{~m}$ (1015 ft) at 71 floors, it is renowned as the first "zero energy" tall building, having been designed to produce as much energy as it consumes. Completed in 2013, the Pearl River Tower serves as a pioneer in green design. The form of the skyscraper not only minimizes wind pressure-reducing the need for structural steel and concrete, and the carbon emissions that are embodied therein - but it also utilizes wind power. That is, the openings at the mechanical floors provide structural relief by allowing for the wind to pass through the building instead of pressing against it. Simultaneously, the tower's innovative form harnesses wind energy by guiding the wind into these openings. The rapid winds push turbines that generate energy for the building's HVAC (Heating, Ventilation, and Air Conditioning) system. The $212,165 \mathrm{~m}^{2}\left(2,281,949 \mathrm{ft}^{2}\right)$ building is also fitted with advanced, double-glazed facades that provide abundant natural light. The outer skin features a high permeability for solar heat, while the inner skin prevents solar gain. The trapped heat rises, creating natural ventilation along the building's facade. Toward the top, exchangers absorb, reuse, and store this rising heat. The inner skins on the eastern and western sides have been made of a triple glazed glass that insulates the building's interior. Given the tower's shallow floor plate, natural light can permeate most of the interior spaces [9]. On the south facade, large-scale solar panels have been installed on the roof and on lower areas, where wind openings are used to generate electricity $[17,18]$. The CTBUH recognized the Pearl River Tower as a Finalist for the "Best Tall Building Asia \& Australasia" in the 2013 Awards Program (Figure 1). 


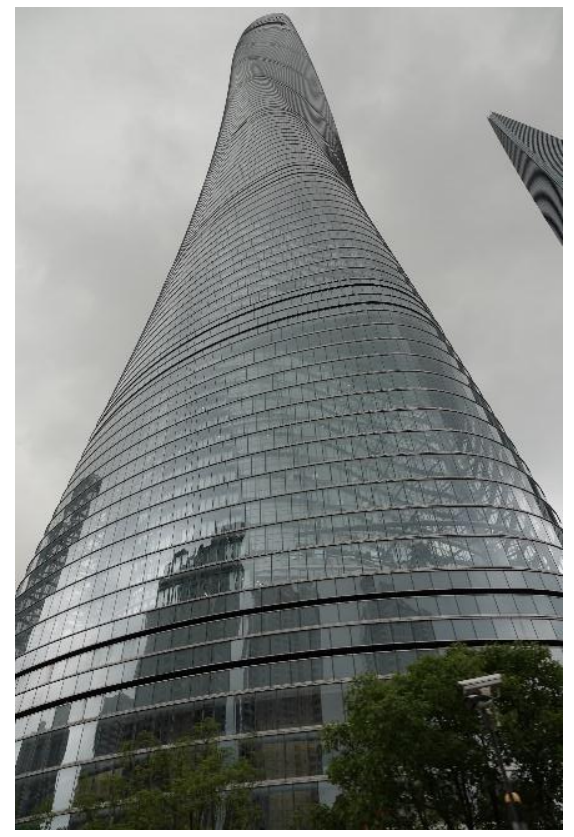

Shanghai Tower, Shanghai, China.

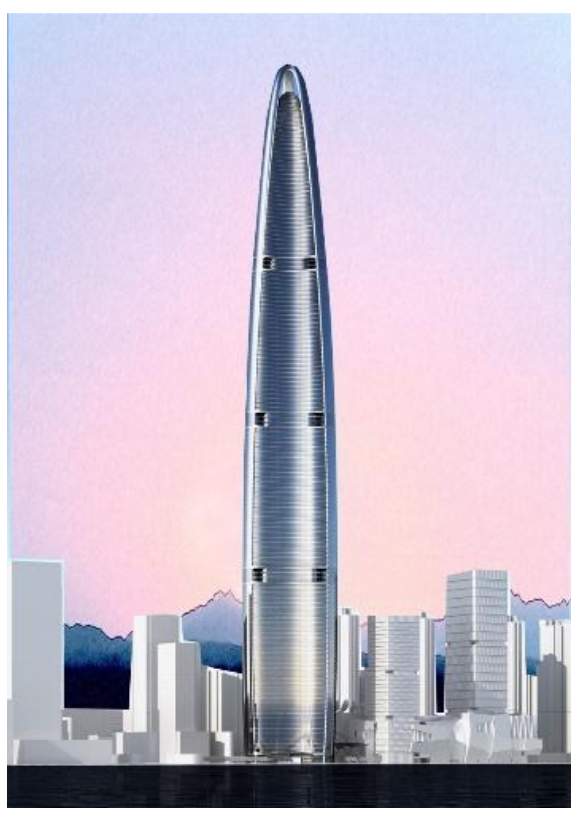

Wuhan Greenland Center, Wuhan, China.

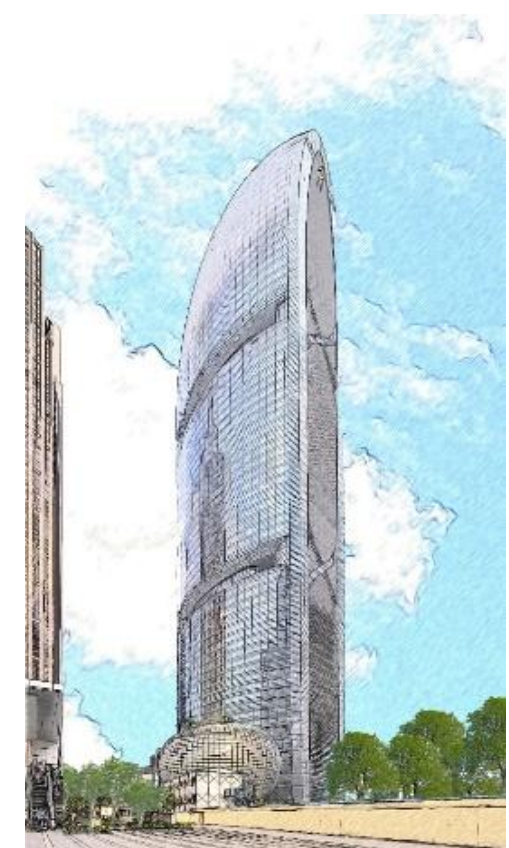

Pearl River Tower,

Guangzhou, China.

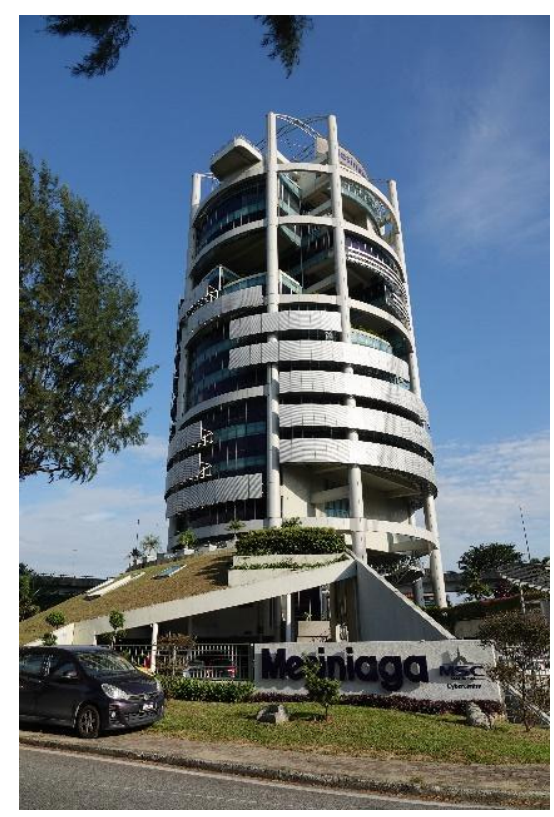

Menara Mesiniaga, Subang Jaya, Malaysia.

Figure 1. Cont. 


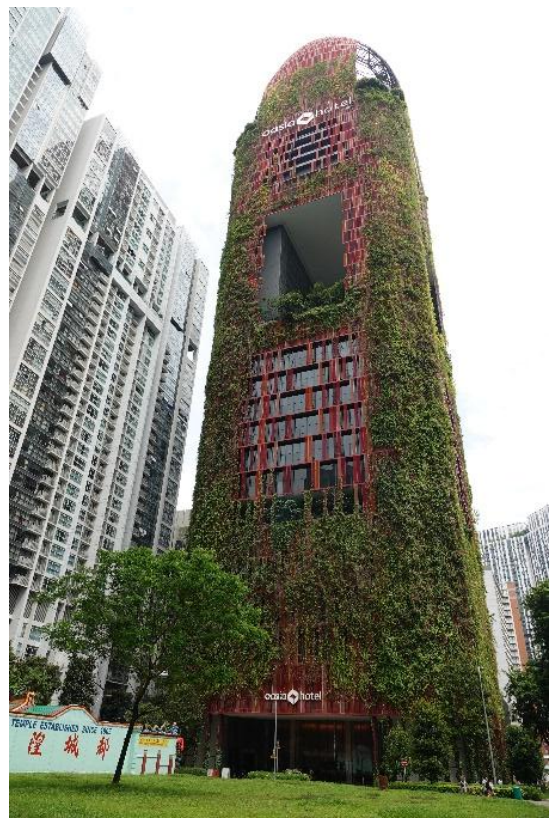

Oasia Downtown, Singapore.

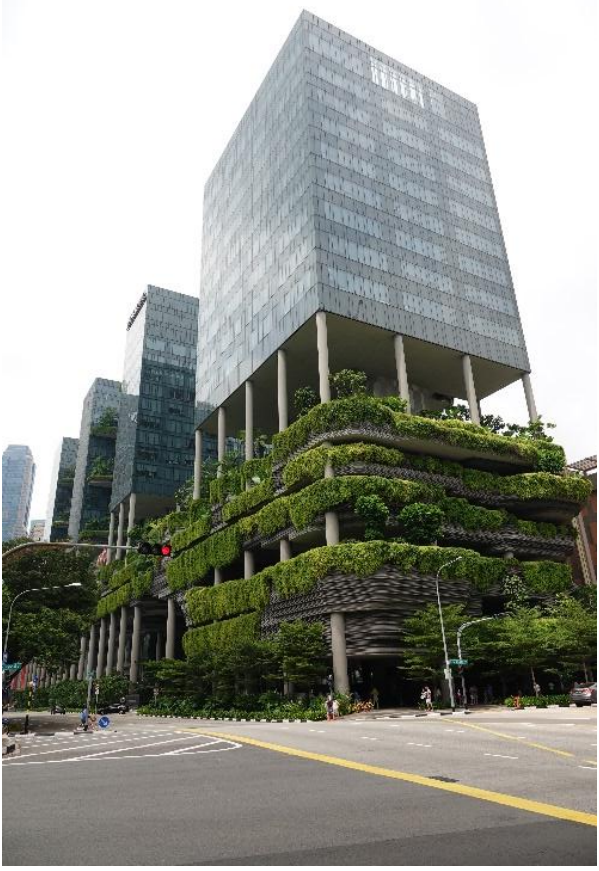

ParkRoyal on Pickering, Singapore.

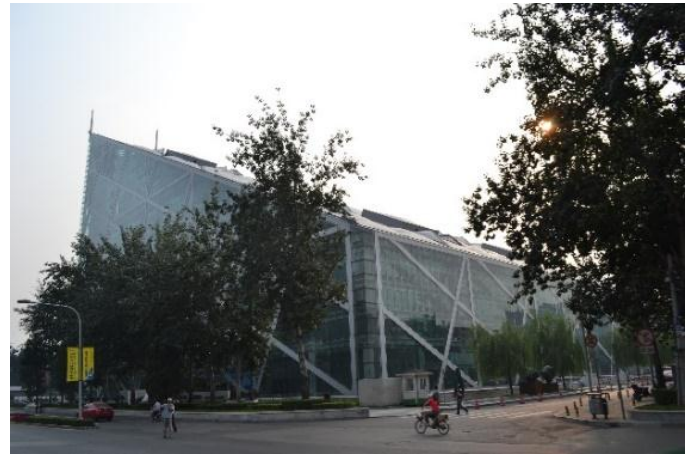

Parkview Green FangCaoDi, Beijing, China.

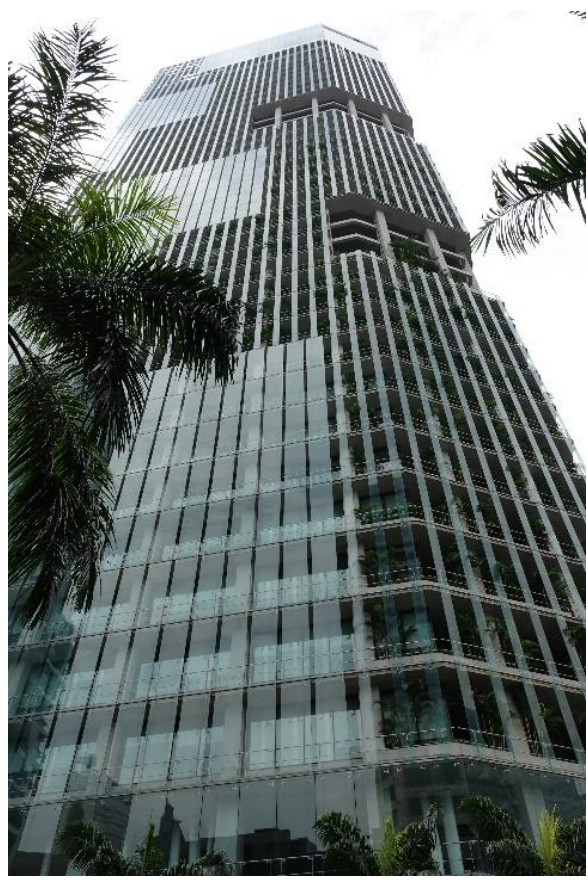

CapitaGreen, Singapore.

Figure 1. Southeast Asia and the Far East.

\subsection{Wuhan Greenland Center}

The Wuhan Greenland Center, which is currently on hold, if completed, will become a new landmark in downtown Wuchang in Wuhan, the capital of Central China's Hubei province. This tower has the potential to transform Wuhan from a regional center to an international city. At a height of $636 \mathrm{~m}$ 
(2087 ft), the 125-story tower will be one of the tallest in the world. The tower maximizes efficiency through adjustments in its form and structural systems, integrating the latest wind engineering technologies. The design features a tripod base that leads to an efficient, aerodynamic profile of three key components: a tapered body, softly rounded corners, and a domed top. These features reduce the wind resistance and vortex shedding that usually cause supertall buildings to sway [14], (Figure 1).

\subsection{Menara Mesiniaga}

Menara Mesiniaga is a well-known eco-skyscraper by Ken Yeang that is located in Subang Jaya near Kuala Lumpur, Malaysia. Its striking design features include a series of vertical plantings, situated along the façade and "skycourts" that start from a three-story high mound and spiral to the roofline of the building. Curtain-wall glazing is used on north and south façades to moderate solar gain, while all of the windows facing the hot east and west façades have external aluminum fins and louvers to provide sun shading. Other features include natural ventilation and ample sunlight. The rooftop terrace is covered with a sunroof of trussed steel and aluminum, which shades and filters light onto the swimming pool and gymnasium. The building also employs a range of automated systems in order to reduce energy consumption ([17], p. 31) (Figure 1).

\subsection{Oasia Hotel Downtown}

Designed by WOHA firm, Oasia Downtown (2016) boasts a 750 percent replacement "green value" by employing a façade of aluminum mesh covered in 20 species of flowering vines and creeper plants. These greeneries provide shade, absorb heat, and cool and purify the air. To facilitate natural ventilation, the architects punctured the vegetated façade by alternating $30 \mathrm{~m}(98-\mathrm{ft})$ open-air sky gardens and employed a series of energy-efficient fans to circulate breeze and cool air around the tower. Aesthetically, the tower takes different forms and shapes as plants grow and change color over seasons. Importantly, the chosen plants that grow over the exoskeleton require minimum maintenance. Patrick Sisson, in his recent (2016) article titled "Tower as Trellis: A Plant-Covered High-Rise Reimagines Tropical Buildings" explains this maintenance issue. He states, "It's a departure from other experimental green high-rises, the Bosco Verticale in Milan, Italy, a celebrated green residential project that employs a team of flying gardeners to maintain the trees and shrubs spread across the building's balconies" [19]. Sisson cites in his article Richard Hassell, the cofounder of WOHA, the Singapore-based firm behind Oasia, explaining: “We're always a little concerned that it's tough to get a pool of laborers who are both Spiderman and gardeners. So for our projects, we always make sure they can take care of themselves without special maintenance or care" [19]. In May 2018, the building won the "CTBUH Best Tall Building Worldwide" award. Among the reasons for winning the award are " . . because it incorporates [many] stories of green walls along the exterior, ... [and] because of its significant commitment to communal space. The tower has given over 40 percent of its volume to open air communal terraces in the sky" [12] (Figure 1).

\subsection{Parkview Green FangCaoDi}

Parkview Green FangCaoDi complex (literally in Chinese, "green, grassy area") is located in the heart of Beijing's CBD (Central Business District). It is an iconic landmark and a potent symbol of creative design thinking that promotes attractive forms, efficient utilities, functionality, and enjoyable experiences. The project was first conceptualized in 2001, completed in 2010, and opened to the public in late 2012. Sheltered by a mega pyramidal envelope, the complex (dubbed the urban pyramid) simulates a city-within-a-city or a "vertical neighborhood". It occupies two city blocks covering an area of $200 \mathrm{~m}$ by $200 \mathrm{~m}$ ( $656 \mathrm{ft}$ by $656 \mathrm{ft}$ ). A spinal bridge connects the two opposite ends of the blocks diagonally allowing for pedestrians to make a walkable shortcut through the complex. Technologically, the mega pyramid's micro climatic envelope comprises a Texlon ETFE (Ethylene Tetrafluoroethylene) membrane system of glass and structural steel facades. The envelope protects tenants and visitors 
from adverse weather conditions while providing an "outdoor" environment with abundant natural light and thermal comfort [15] (Figure 1).

\subsection{ParkRoyal on Pickering}

Completed in 2013, ParkRoyal on Pickering in Singapore offers office and hotel spaces and it has been widely recognized for its vegetative scheme that features large balconies, sky gardens, and terraces (total of $15,000 \mathrm{~m}^{2}\left(161,459 \mathrm{ft}^{2}\right)$ )that contain tropical plants, water features, and green walls. As such, this complex achieved more than $200 \%$ of the site area in green replacement. Lush landscaping, plants, and shrubs permeate throughout and they are brought directly to the guestrooms and public areas [14]. Interestingly, the podium design embraces a "geological form" that echoes topographical contours, which is vividly seen in the faced and ceilings (Figure 1).

\subsection{CapitaGreen}

Also located in Singapore's Central Business District (CBD), CapitaGreen features lush greenery (vegetation covers $55 \%$ of the perimeter of its facade) with the intention to reconnect people to nature and reintroduce the greenery that was present on the site before it was developed. The $242 \mathrm{~m}(794 \mathrm{ft})$ tower employs a double-skin facade that consists of an outer skin of frameless glass and an inner skin of double-glazed floor-to-ceiling glass that reduces solar heat gain by up to $26 \%$. The facade also incorporates a maintenance ledge that facilitates easy access to the greenery. In addition to double-skin and greenery features, the building integrates a "wind scoop" that pulls in cooler air from the outside and channels it to each floor through an inner "air well" [14]. CapitaGreen received the CTBUH 2015 Best Tall Building Award for Asia \& Australasia Region. It was completed in 2014 (Figure 1).

\section{The Middle East}

\subsection{Bahrain World Trade Center}

Designed by Atkins Design Studio, the Bahrain World Trade Center (BWTC) in Manama, Bahrain is a twin-tower complex that is largely considered to be the first in the world to incorporate large-scale wind turbines to harness wind power. The 45 -story, $240 \mathrm{~m}(787 \mathrm{ft})$ mixed-use towers contain a hotel, shopping center, and offices. The striking feature of the towers is three massive wind turbines that measure $29 \mathrm{~m}(95 \mathrm{ft})$ in diameter and are supported by bridges that span the two buildings. They generate about $15 \%$ of the buildings' power. Each tower embraces a curvilinear profile that funnels the existing on-shore Gulf breeze into the prominent wind turbines [16]. Placed conspicuously between the twin towers, the three massive turbines evoke a strong visual nod toward sustainability. These two towers, the second tallest in Bahrain, were completed in 2008, winning the CTBUH Best Tall Building in the Middle East and Africa Award that same year (Figure 2).

\subsection{Doha Tower}

Doha Tower is a 46-story, $238 \mathrm{~m}(781 \mathrm{ft})$ high-rise that is located in the West Bay of Doha, Qatar. Designed by Jean Nouvel, Doha Tower's cylindrical form was designed to consider multiple factors, such as efficiency, daylight, wind resistance, and iconicity. The core of the building is off-center, allowing for more flexible office spaces. The exterior cladding evokes the traditional Islamic "mashrabiyya", a popular form of wooden lattice screen found in vernacular Islamic architecture used to achieve privacy while reducing solar glare and heat gain. Placed along the building's façade, the "modernized mashrabiyya" uses a single geometric motif overlaid at several scales and densities to produce the desired effect. That is, the overlays correspond to the local solar dynamics with a $25 \%$ opacity at the north elevation, a $40 \%$ at the south elevation, and $60 \%$ at the east and west elevations. Overall, the building's façade is estimated to reduce cooling loads by $20 \%$. Completed in 2012, Doha Tower has received the CTBUH Skyscraper Award for the Best Tall Building Worldwide that same year [16] (Figure 2). 


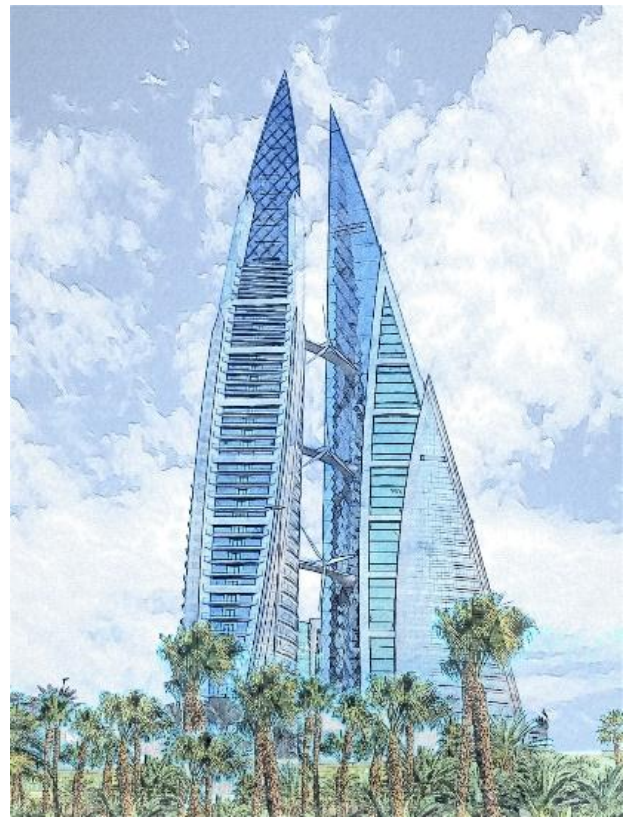

Bahrain World Trade Center, Manama, Bahrain.

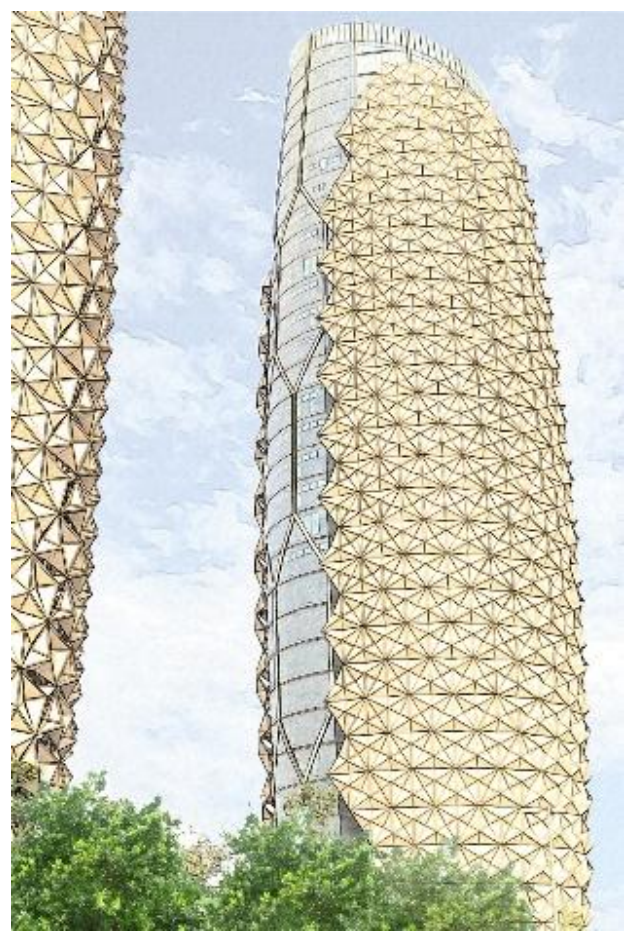

Al Bahar Towers, Abu Dhabi, UAE.

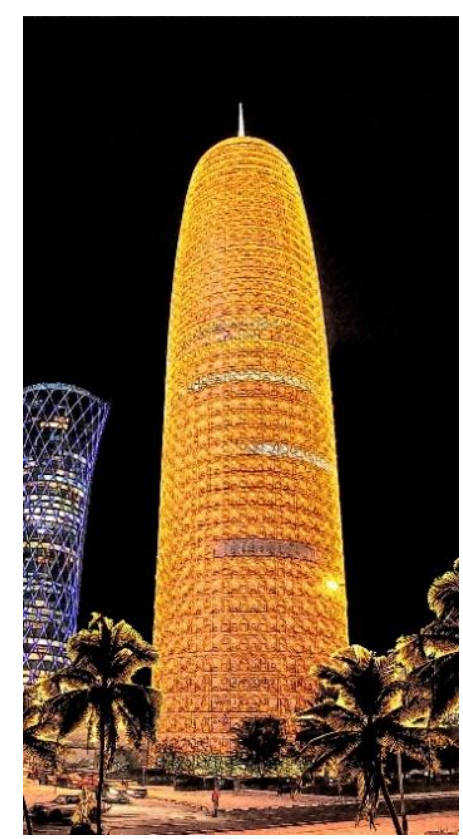

Doha Tower, Qatar.

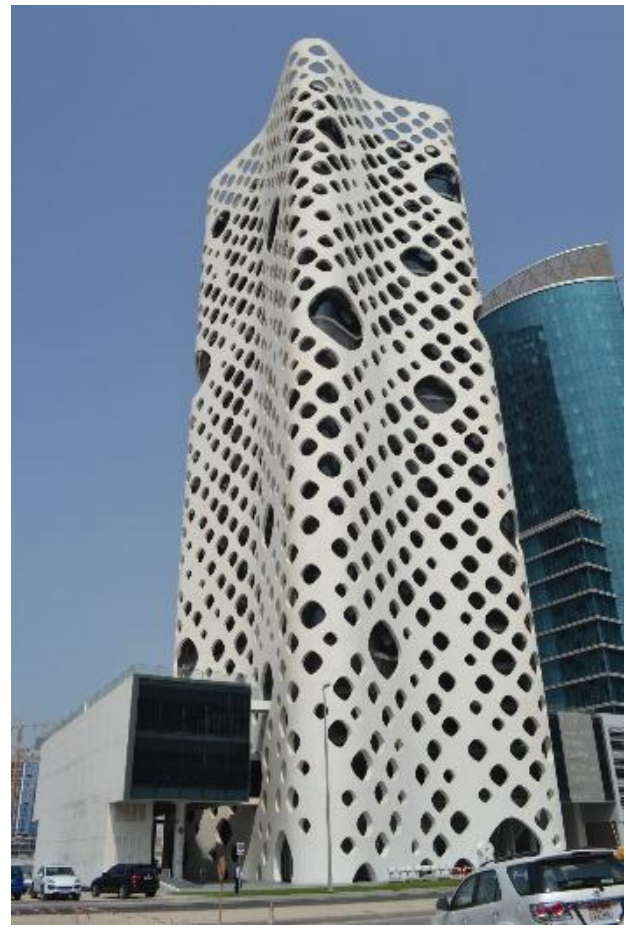

O-14 Building, Dubai, UAE.

Figure 2. Cont. 


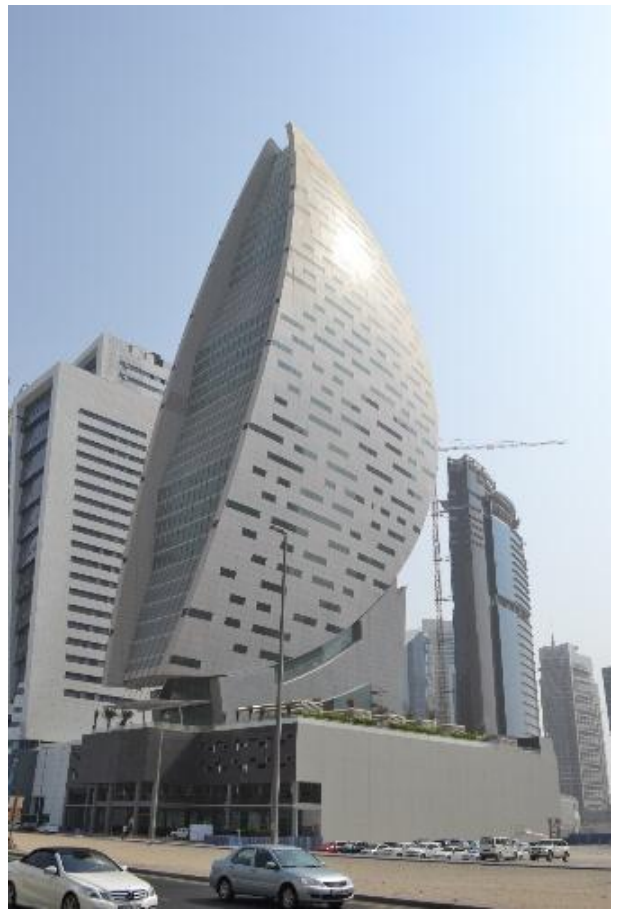

Iris Bay, Dubai, UAE.

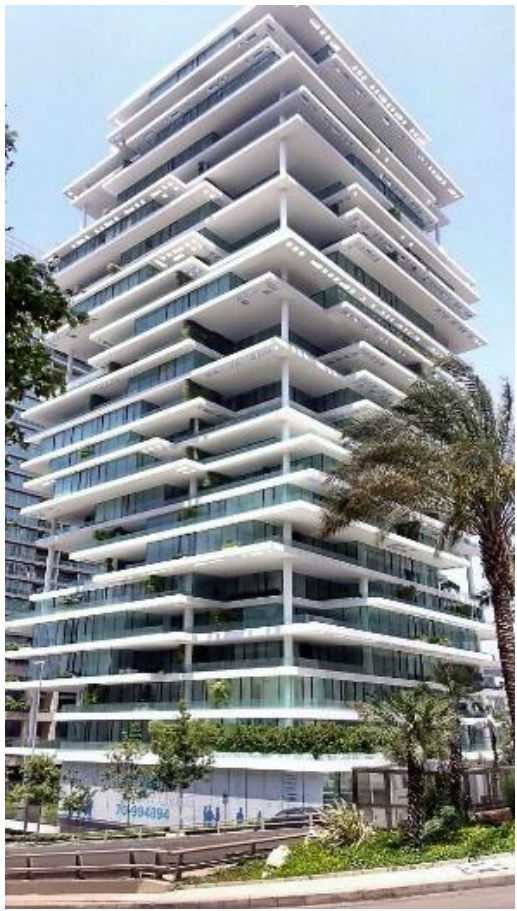

Beirut Terraces, Beirut, Lebanon.

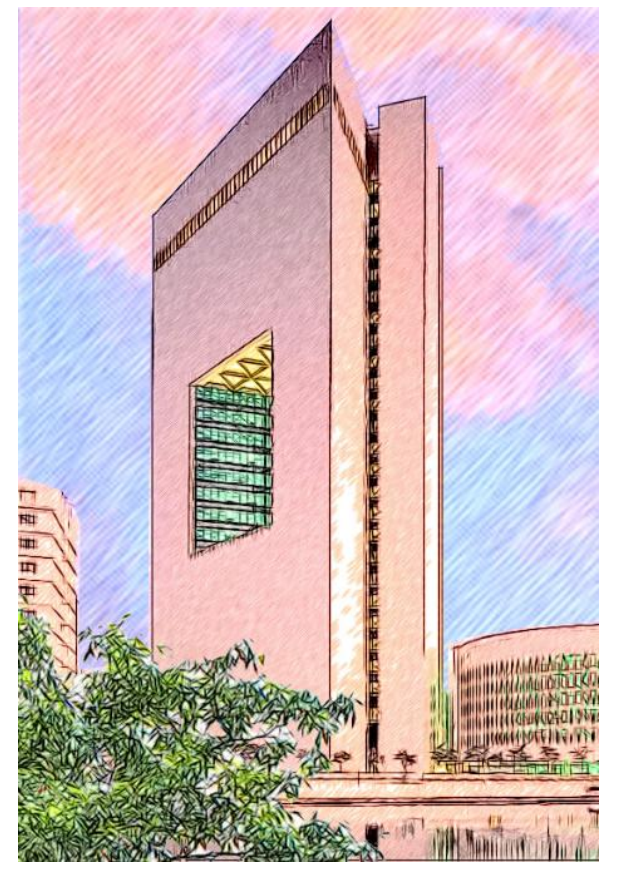

National Commercial Bank, Jeddah, Saudi Arabia.

Figure 2. The Middle East. 


\subsection{Al Bahar Towers}

Completed in 2012, Al Bahar Towers house the new headquarters for the Abu Dhabi Investment Council. Occupying a prominent site on the North Shore of Abu Dhabi Island in UAE, the project

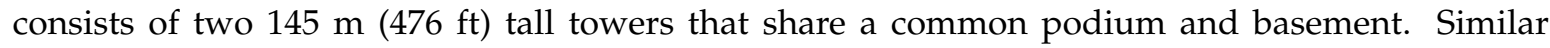
to Doha Tower, Al Bahar Towers take inspiration from traditional Islamic motifs, integrating the mashrabiyya into an innovative, automated shading system. In other words, the building's dynamic façade has been conceived as a contemporary interpretation of traditional Islamic architectural forms. However, the mashrabiyya system of Al Bahar Towers contains a series of translucent umbrella-like units that open and close in response to the sun's movement [14]. Each of the two towers contains over 1000 individual shading devices, consisting of stretched PTFE (polytetrafluoroethylene), which are controlled by a centralized building management system (BMS). In 2013, the CTBUH recognized Al Bahar Towers as the "CTBUH Innovation Award Winner" and a "Best Tall Building Middle East \& Africa Finalist" (Figure 2).

\section{4. $0-14$}

Completed in 2010, O-14 is a 24 story-tall high-rise in Dubai, UAE that has employed a unique exoskeleton concrete façade with circular openings. Designed by RUR Architecture, the building's unique exterior serves as solar screens that protect the glass curtain wall from the harsh desert sun, while providing daylight and framing views to the outside. The one-meter space between the façade and the building's glass surface also yields a chimney effect whereby hot air rises to create an efficient passive cooling system. The façade also serves as a structural exoskeleton that bears the lateral loads of the tower [20]. In 2012, the CTBUH recognized O-14 as a "Best Tall Building Middle East \& Africa Finalist". The council praised the building's exoskeleton by stating, "The curvaceous, porous form creates a sculptural shell that is monumental and ambiguous on the exterior and intimate and sheltered on the interior" [12] (Figure 2).

\subsection{Iris Bay}

Designed by Atkin, Iris Bay offers another example of a visually expressive sustainable tower. Completed in 2015, this office tower sits in the burgeoning Business Bay district in downtown Dubai, near Burj Khalifa, the world's tallest tower. Similar to neighboring towers, it rests on a four-story podium. However, its mass is distinctly different by offering a sculptural form that effectively responds to the region's hot and arid climatic conditions. The tower's southwest and northeast facades feature fewer openings to limit solar exposure; they also incorporate photovoltaic cells to harness solar energy. Meanwhile, the northwest façade—which has least solar exposure-features a floor-to-ceiling zigzagging curtain wall that allows in natural light and fresh air. The opposite façade integrates balconies with varying depths that correspond to the sun path, shading the spaces below. The convex-shaped facades also reduce the effect of prevailing winds on the building and hence decrease the required structural materials. The elliptical form also creates areas of negative pressure that draw air into the building, allowing for cross natural ventilation. Engineers placed mechanical floors in the center of the tower for a more efficient distribution of services. Further, the tower's podium hosts a wide-range of amenities and services, including retails, gym, prayer room, swimming pool, and 920 underground parking spaces. Moreover, architects placed green roofs atop the podium and the tower. In 2016, the CTBUH recognized Iris Bay as a "Best Tall Building Middle East \& Africa Finalist" [12] (Figure 2).

\subsection{Beirut Terraces}

The "green veil" tower is spreading globally beyond tropical regions. Recently, Jacques Herzog and Pierre de Meuron have completed Beirut Terraces in Beirut, Lebanon. The building's striking feature is staggered plant-covered, generous terraces that are made of white, slim slabs, creating a 
"hanging gardens" effect. Corner white columns support terraces, while glazed balustrades follow the perimeter. The idea of emphasizing outdoor living (for both people and plants) is suitable to the moderate climate of Beirut and its local culture. The 27-story building consists of five modular floors that rise in different combinations to create a dynamic composition. The $119 \mathrm{~m}(392 \mathrm{ft})$ tower offers apartments of different sizes (from $210-\mathrm{m}^{2}$ one-bedroom units to $1050-\mathrm{m}^{2}$ penthouses) and designs, as well as various amenities, including spa, pool, sauna, steam, massage rooms, and shopping facilities [14] (Figure 2).

\subsection{National Commercial Bank}

A notable eco-tower that preceded the Green Movement and responded to climatic conditions is SOM's 27-story National Commercial Bank (1987) built in Jeddah, Saudi Arabia. The isosceles triangle-shaped office tower significantly departs from the Modernists' steel-and-glass model by employing opaque walls punctuated by three dramatically large openings- $30 \mathrm{~m}$ by $30 \mathrm{~m}(100 \mathrm{ft}$ by $100 \mathrm{ft}$ ) - that create internal shaded sky gardens or "vertical courtyards". Office windows open directly onto the courtyards. With an inward orientation, typical of traditional Arabic-Islamic design, these windows can open up to the cooler central courtyard. The deep apertures carved into the sides of the building provide shade and natural light for office spaces, which employ gray glazing to mitigate glare. Windows at the top floor, which houses the executive offices, are recessed $3 \mathrm{~m}(10 \mathrm{ft})$ to protect the tenants from sun and glare. In addition, the building's vertical courtyards reduce air temperatures slightly before the intake air is used by air-conditioning machinery. The thermal mass provided by the opaque wall mitigates the rapid transference of excessive heat into the building. The tower is clad in $1.5 \mathrm{~m}$ by $2.7 \mathrm{~m}$ ( $5 \mathrm{ft}$ by $9 \mathrm{ft}$ ) panels of honed Roman travertine, which is suitable to Jeddah's humid climate. Although the resulting appearance of the building has been controversial, the innovative "vertical courtyard" concept is well rooted in the local culture and climate [14] (Figure 2).

\section{Europe}

\subsection{St Mary Axe}

Designed by Foster and Partners, 30 St Mary Axe is an example of high-performance design and

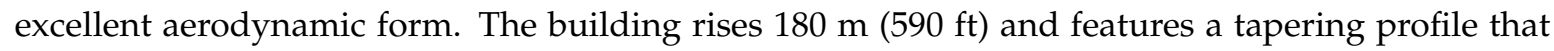
reduces downward gusts of turbulent wind. The form also disperses reflected light, thereby enhancing its environmental effects. The employed steel spiral "diagrid" system and the aerodynamic form of the building improve the structure's wind resistance. Its office spaces are arranged around a central core that contains elevators, side rooms, and fire escapes. Circular floor plans may pose an interior layout challenge. Foster worked around the problem by creating six rectangular spaces (spokes or fingers) that radiate from the center where the core is located containing services and elevators. The triangle voids between these fingers were turned into atria. Each floor rotates five degrees resulting in spiral atria or light wells that provide natural light and ventilation (forming the building's lung) through automatically operable windows. These atria also provide strong visual interconnectivity between the floor spaces. To meet fire code requirements, the spiral atria are interrupted every six floors so that updrafts of air do not become too strong. Importantly, the circular glass facades and the column-free floor plan reduce the need for artificial lighting. The artificial lighting systems in the building use motion sensors to reduce unnecessary lighting. In 2004, the tower won the United Kingdom's top architectural accolade, the Stirling Prize, from the Royal Institute of British Architects; and in 2013, the Council on Tall Buildings and Urban Habitat (CTBUH) honored 30 St Mary Axe with the first recipient of the 10 Year Award. The CTBUH has created this award to recognize proven value and performance, across one or more wide-ranging criteria in building design, over a period of at least 10 years (Figure 3 ). 


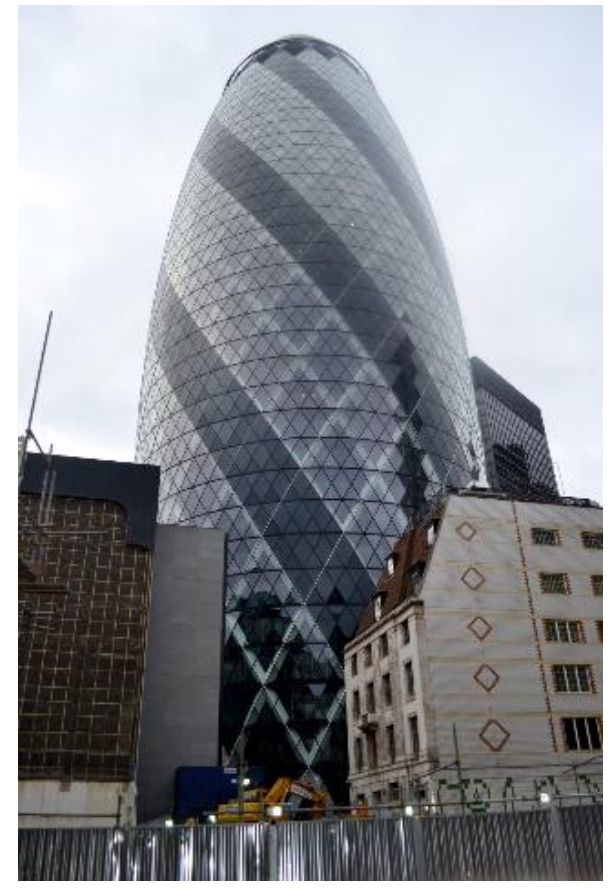

30 St Mary Axe, London, UK.

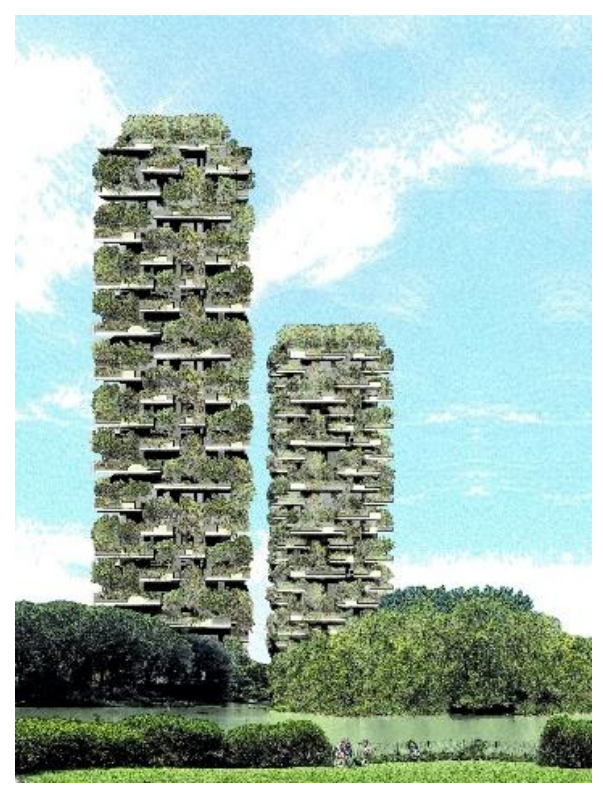

Bosco Verticale, Milan, Italy.

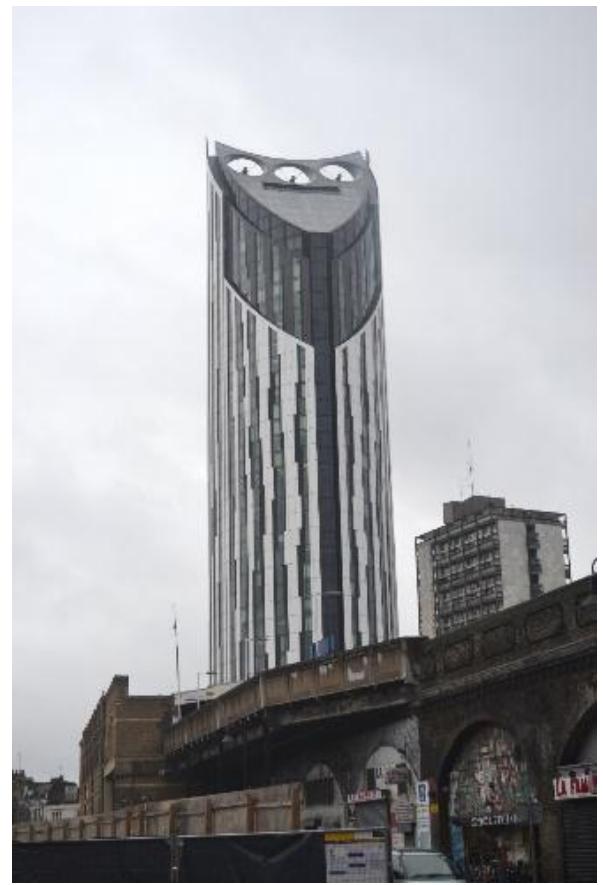

Strata SE1 Tower, London, UK.

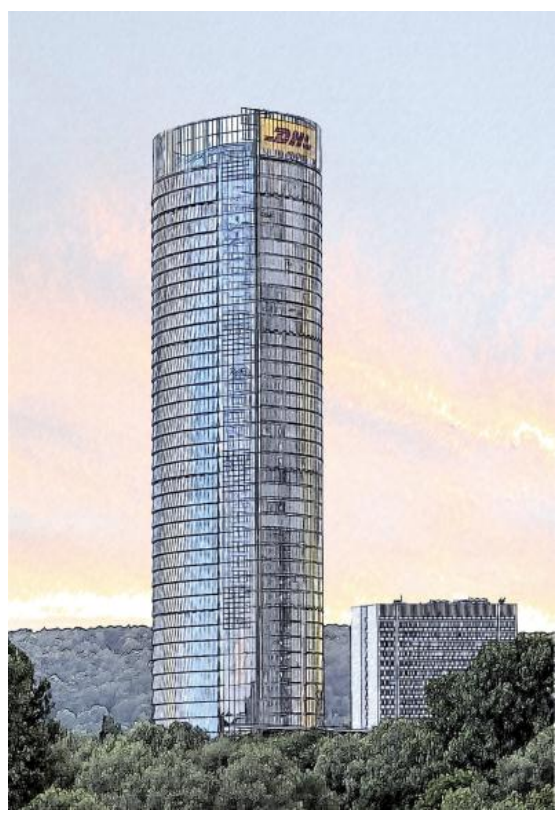

Post Office Tower, Bonn, Germany.

Figure 3. Cont. 


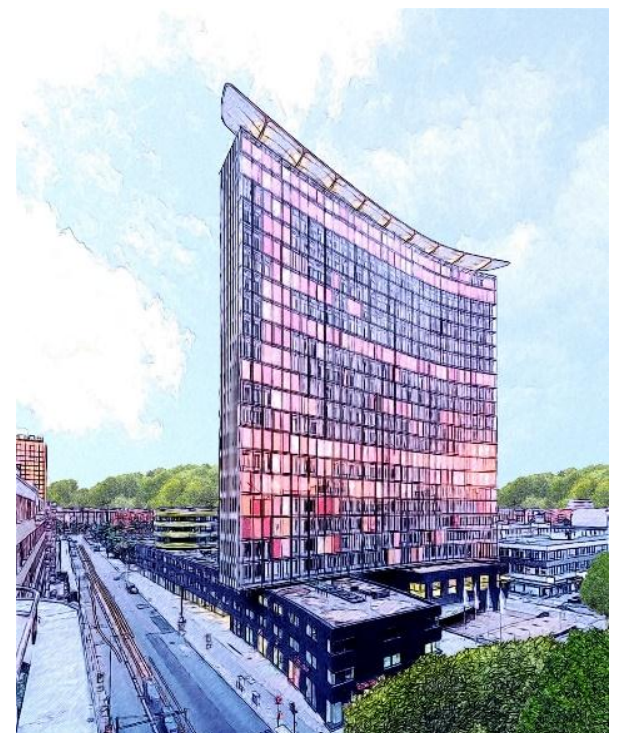

GSW Headquarters, Berlin, Germany.

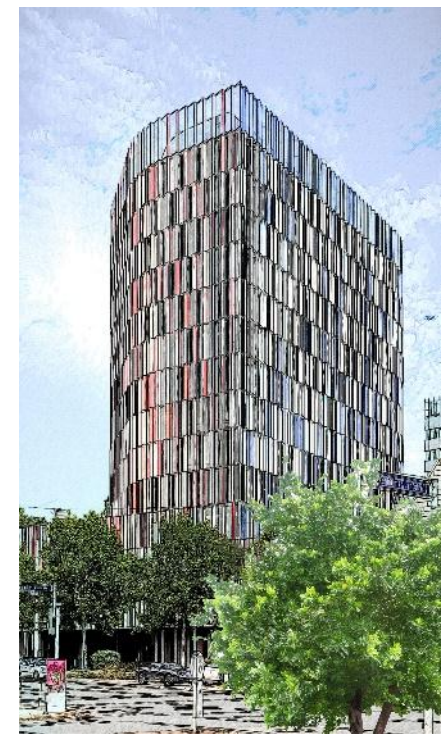

KfW Headquarters, Frankfurt, Germany.

Figure 3. Europe.

\subsection{Strata SE1 Tower}

The Strata SE1 Tower is a $148 \mathrm{~m}(485 \mathrm{ft}), 43$-story building at Elephant and Castle in the Borough of Southwark, London. Designed by BFLS (formerly Hamiltons), it is one of the tallest residential buildings in London containing 408 apartments for over 1000 residents. The tower is one of the first buildings in the world to incorporate wind turbines within its form, with three $9 \mathrm{~m}(30 \mathrm{ft})$ wind turbines producing enough energy to power the building's common areas. The three turbines are rated at $19 \mathrm{~kW}$ each and produce about $50 \mathrm{MW} / \mathrm{h}$ of electricity annually, or $8 \%$ of the Strata's total estimated energy consumption. Strata Tower also uses post-tension slabs to reduce slab thickness, enabling greater floor-to-ceiling heights, and eventually developing a high-performance, three-layer, aluminum-and-glass façade. The building enjoys a tripartite structure of base, middle, and top; and it was completed in 2010 [15] (Figure 3).

\subsection{Bosco Verticale}

Lack of green spaces and an abundance of "concrete jungles" prevail in myriad cities. At the heart of Milan, the Bosco Verticale, or "Vertical Forest" tries to balance the urban with the natural. The pair of residential towers is festooned with concrete decks, staggered, and offset from one another, giving the structures a forest-like appearance. Completed in 2014, the project features about 800 trees (each measuring 3, 6, or $9 \mathrm{~m}(10,20$ or $30 \mathrm{ft})$ tall), alongside a wide-range of shrubs and flowers on $8900 \mathrm{~m}^{2}$ $\left(96,000 \mathrm{ft}^{2}\right)$ of terrace spaces. These are placed mainly on large, staggered, cantilevered balconies at a gracious height of two stories. The project also employs a photovoltaic-based energy system that produces electricity, making the project nearly energy self-sufficient. The two towers-at 19 floors, $85 \mathrm{~m}$ (279 ft) tall, and 27 floors, $116 \mathrm{~m} \mathrm{(380} \mathrm{ft)} \mathrm{—accommodate} \mathrm{a} \mathrm{total} \mathrm{of} 400$ condominium units [21]. In 2015, Bosco Verticale won the "CTBUH 2015 Best Tall Building Worldwide Award." One of the jurors stated: "The Bosco Verticale 'vertical forest' in Milan, Italy, takes the definition of 'green skyscraper' to a new level, deploying more than 13,000 plants across $90+$ species, including full-sized trees, on all façades of both its towers" [12] (Figure 3). 


\subsection{Post Office Tower}

Completed in 2002, the 41-story, $163 \mathrm{~m}$ (535 ft)-high Post Office Tower (also known as the Deutsche Post Tower and Post Turm) is the headquarters of the logistic company Deutsche Post DHL in Bonn, Germany. The tower rises from a park-like environment near the riverbank of the Rhine River. The floor plan of the tower consists of two staggered semi-ellipses (east-west axis) spaced $7.4 \mathrm{~m}$ (24 ft) apart, which create two separate buildings. This floor plan's arrangement provides multiple functions, including structural, programmatic, and aesthetic benefits. Dividing the tower's mass into smaller sections makes it appear lighter, slenderer, and more elegant. The floor plan's articulation also facilitates multiple sharp edges at the opposite ends of the tower, which strengthen the tower's profile by evoking a powerful sense of verticality. To provide natural ventilation and daylighting, as well as to save on energy, the tower employs multiple green features, including sky gardens, double skin facade, and water is pumped from the nearby Rhine River. The building's supply of natural ventilation reduces the need for mechanical systems, air-conditioning components, and ventilation ducts that take up a significant proportion of the interior space, saving on operational costs. The most striking feature of the Post Office Tower, however, is its highly transparent form, which was made possible through the use of glass in many of the buildings' components, including curtain walls, sky garden floors, lifts, interior partitions, windows and doors, escape routes (with fire-resistant glass), and related elements. All of the glass used is white, which possesses a higher transparency than ordinary glass. Indeed, the abundant use of highly transparent glass gives the building a special character from wherever one experiences it: inside, nearby, or from a distance [16], (Figure 3).

\subsection{GSW Headquarters}

The GSW (Gemeinnützige Siedlungs—und Wohnungsbaugesellschaft $\mathrm{mBH}$ ), which translates to the Charitable Settlement and Housing Association Ltd., is located about $250 \mathrm{~m}(820 \mathrm{ft})$ from the former Berlin Wall and the historical site of Checkpoint Charlie, occupying a sensitive place in the urban cultural fabric of the city. Berlin-based Sauerbruch Hutton Architects designed the GSW tower. The firm is renowned for creating functional and sensual architecture achieved using dynamic colors and fluid curvilinear forms. Completed in 1999, the 22-story, $85 \mathrm{~m}$ ( $250 \mathrm{ft}$ )-high GSW tower is an exemplar of ecological architecture - often referred to as "Germany's first ecological high-rise" - for integrating numerous sustainable features that facilitate natural ventilation (stack and cross ventilation) and daylighting. Some of the strategies employed include a narrow floor plate, automatically and manually operated windows, sun screening, blinds, thermal storage, stack heating, and a double-skin thermal flue on the west facade. The layout of existing buildings on the site forces an undesirable east-west orientation to the tower. In response, the architects designed the west facade as a double-skin system with a thermal flue, which provides automatic and manually operated triple-glazed windows on the inner skin. The outer skin contains fixed single-glazed panels that consist of $3.3 \mathrm{~m}, 1.8 \mathrm{~m}$, and $10 \mathrm{~mm}$ $(11 \mathrm{ft}, 6 \mathrm{ft}, 0.4 \mathrm{in})$ glass panes. The inner skin consists of Low-E double-glazing. The interstitial space of $0.9 \mathrm{~m}(3 \mathrm{ft})$ contains shading devices, a series of vertically pivoting and sliding louvers, which shut out the unwanted light of the harsh afternoon sun [16]. The louvers are made of $0.6 \mathrm{~m}(2 \mathrm{ft}$ )-wide and $2.9 \mathrm{~m}$ (9.5 ft)-high aluminum panels and are colored red, pink, and orange. These rich colors along with the building's flying roof sculpture make the GSW Headquarters an instantly recognizable building (Figure 3).

\subsection{KfW Headquarters}

KfW (Kreditanstalt für Wiederaufbau, or Credit Buro for Reconstruction) is a government-owned mid-size bank in Frankfurt, Germany. The new 14-story, 39,000 $\mathrm{m}^{2}\left(419,792 \mathrm{ft}^{2}\right)$ extension to the KfW Banking Group's headquarters completes an existing ensemble of heterogeneous buildings from the last four decades by adding 700 new offices. The iconic office tower takes on a flowing form, rising 10 stories from a four-story podium. Designed by the Berlin-based Sauerbruch Hutton 
Architects, the building aimed to achieve an outstandingly low energy consumption rate of $98 \mathrm{kWh} / \mathrm{m}^{2}$ $\left(1055 \mathrm{kWh} / \mathrm{ft}^{2}\right)$ per year. Sauerbruch Hutton crafted an aerodynamic form for the $\mathrm{KfW}$ building and strategically positioned it to effectively respond to prevailing winds and the sun's path. The building possesses a lively colorful exterior, which is a remarkable feature of Sauerbruch Hutton architecture. The visual characteristics of the building are enhanced by the polychromy of the facade's narrow ventilation flaps with different hues of red, blue, and green. The color composition is dynamic; that is, the changing position and setting of the ventilation panels result in a vibrant play of color across the facade. The rich color scheme was inspired by the surrounding cityscape: green tones represent the Palmengarten, reds represent the Main sandstone prevalent in Frankfurt, and the blues complement the color scheme of KfW's refurbished building ([16], p. 21). The building's fluid form and colorful texture enhance the visual expression of the exterior from every angle. Further, the voluminous, $56 \mathrm{~m}$ $(180 \mathrm{ft})$-tall building has been well integrated into the cluster of existing towers enhancing the skyline with a curvy four-story podium that is defined by the edge of Zeppelinallee road (Figure 3).

\section{North America}

\subsection{Bank of America (BoA) Tower}

Bank of America is one of the world's major financial institutions, serving a wide range of businesses and corporations with a full range of banking activities. The tower brilliantly merges the ethics of the green building movement with aesthetics of transparency. In this way, BoA Tower takes on a striking architectural form by innovatively reviving the traditional grammar (components) of the skyscraper-the base, shaft, and top. Its base is distinguished by the use of clear glass that blurs the boundaries of indoors and outdoors, as well as by a podium topped with a garden. The tower's crown is distinguished by a slanted roof, while its shaft draws from the structure of quartz, diffusing light in a crystalline fashion. "With its chamfered top and crystalline geometry, the form of the building eschews the orthogonal blocks of the Modernist tradition creating a sculptural addition to the New York skyline without sacrificing the efficiency and functionality of the office floor plans" [16]. The building's power comes from an on-site cogeneration plant, which works in concert with an ice storage system to reduce the building's peak energy demands. A clean-burning, 5.0-megawatt (MW) cogeneration plant provides approximately $65 \%$ of the building's annual electricity and it lowers the daytime peak demand by $30 \%$ ([16], p. 232). A thermal storage system, consisting of 44 storage tanks, further reduces peak loads on the city's over-taxed electrical grid by producing ice at night that melts during the day to supplement the cooling system. Ice storage systems provide approximately $25 \%$ of the building's annual cooling requirements. Moreover, because it is activated during off-peak nighttime hours when the electricity charging rate is reduced, this ice battery system saves on operational costs. The tower's construction was completed in 2009. It was recognized as the "Best Tall Building Americas Winner" in the 2010 CTBUH Awards Program (Figure 4).

\subsection{New York Times Tower}

The 52-story, $319 \mathrm{~m}$ (1047 ft) tall New York Times Tower was designed by the Italian architect Renzo Piano in collaboration with FXFOWLE Architects, with interiors being done by Gensler. Completed in 2007, its chief tenant is The New York Times Company, publisher of The New York Times as well as the International Herald Tribune, and other newspapers. Among the green features of the building are solar screens of ceramic rods, automated skylights, on-site cogeneration, and a courtyard garden. The steel-framed tower, cruciform in plan, utilizes a screen of thin horizontal ceramic rods mounted to the exterior glass curtain walls on the east, west, and south facades-this forms the building's most original and striking feature. The vertical arrangement of the rods resembles lines

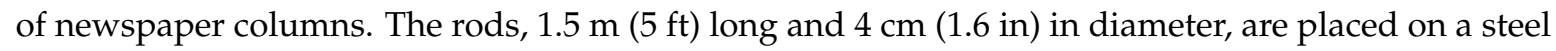
framework of $0.46 \mathrm{~m}(1.5 \mathrm{ft})$ in front of the Low-E glass curtain-wall. These ceramic rods, totaling 186,000 separate pieces, create a second skin around the curtain walls. They diffuse sunlight, block 
direct sunlight, absorb the sun's heat, and result in reduced cooling loads, giving the exterior a clean and uniform appearance. Other green features include curtain walls that are fully glazed with Low-E glass, maximizing natural light within the building. Mechanized shades controlled by sensors reduce glare, while more than 18,000 individually dimmable fluorescent fixtures supplement natural light, providing an energy savings of 30\%. The tower was completed in 2007 [16] (Figure 4).

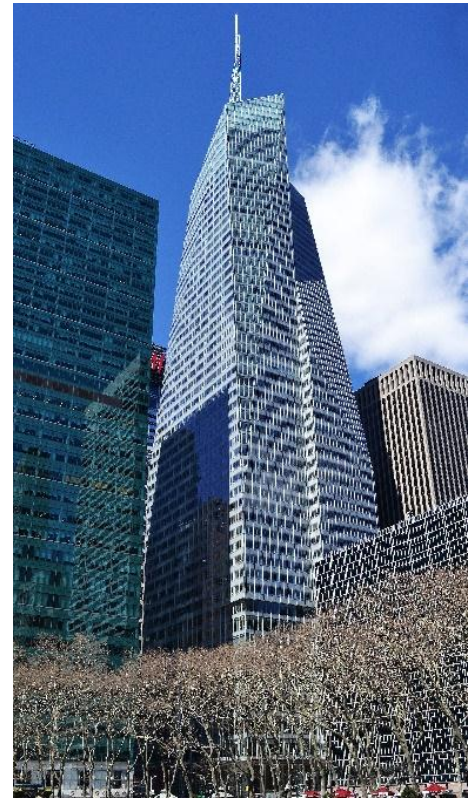

Bank of America (BoA) Tower, NYC.

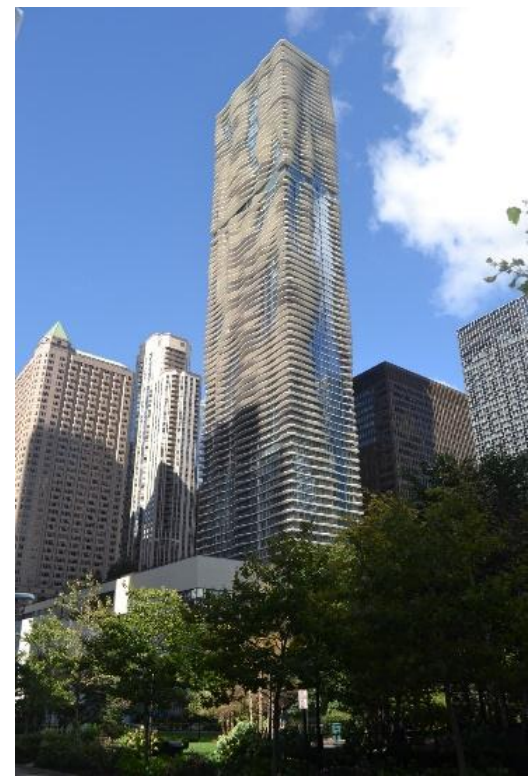

Aqua Tower, Chicago, IL.

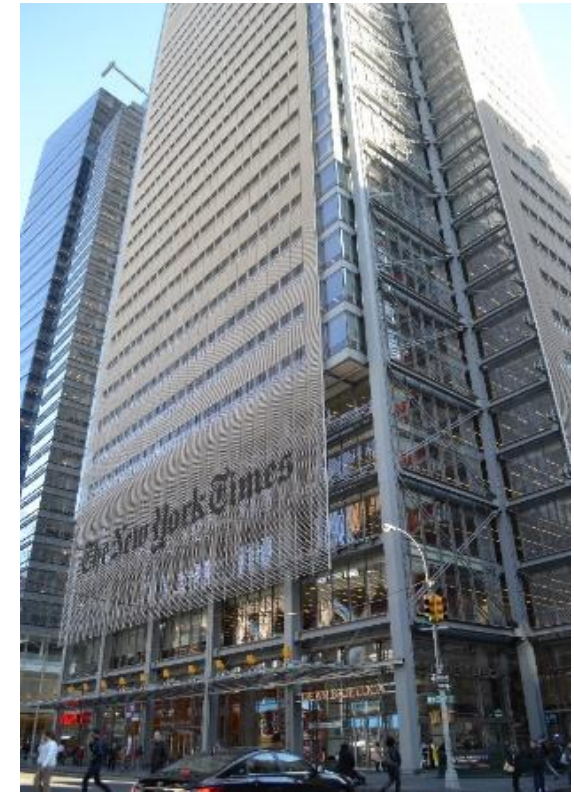

New York Times Tower, NYC.

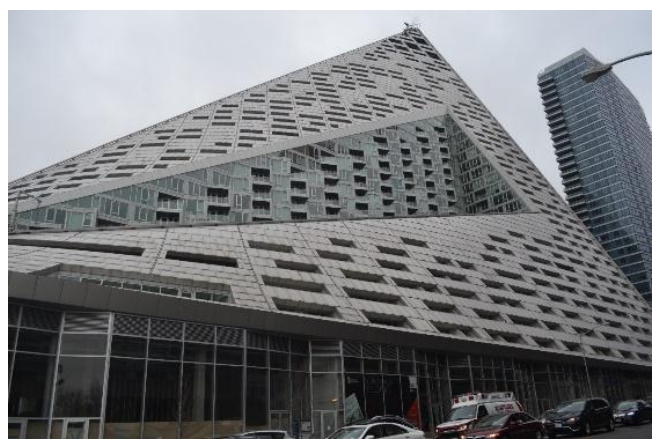

VIA 57 WEST, NYC.

Figure 4. Cont. 


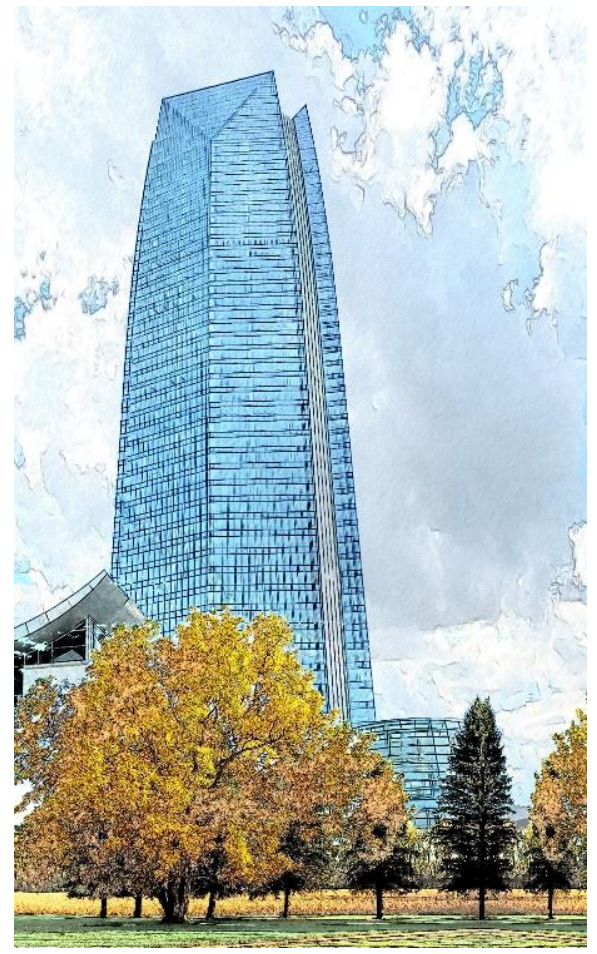

Devon Energy Center, Oklahoma City, OK.

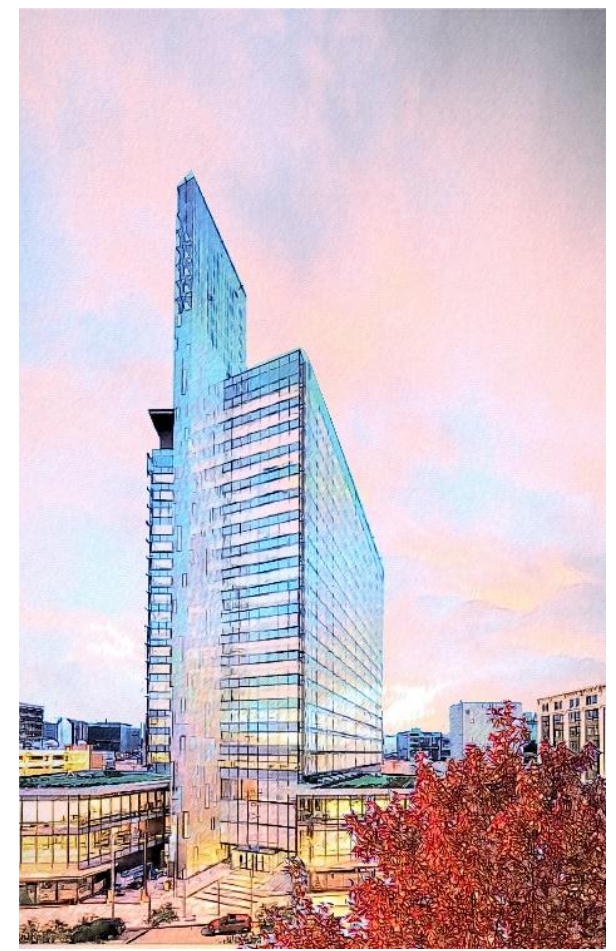

Manitoba Hydro Place (MHP), Manitoba, Canada.

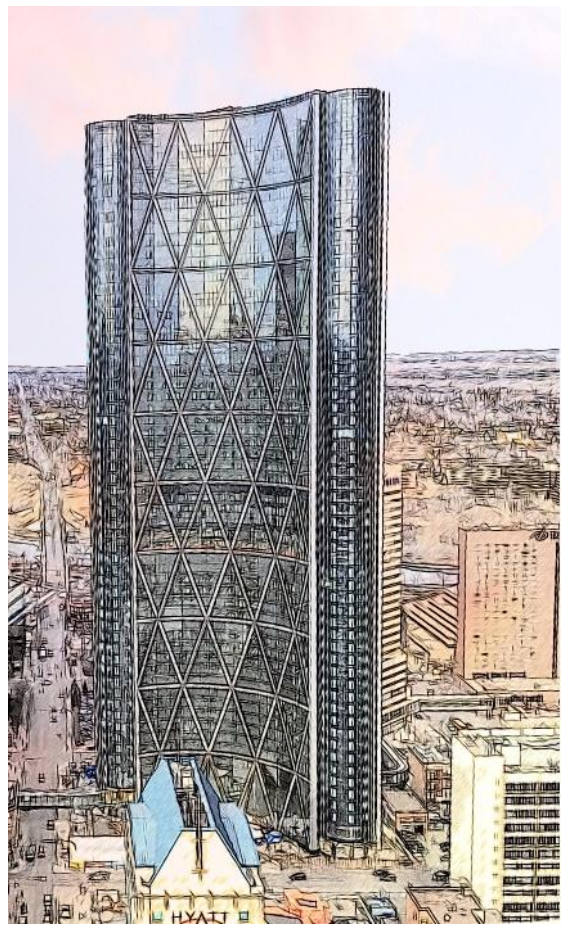

The Bow, Calgary, Canada.

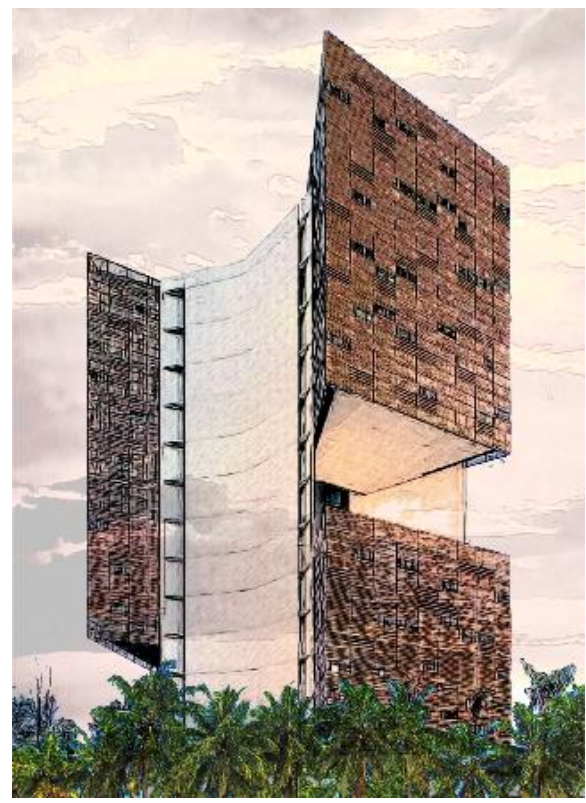

Torre Cube, Guadalajara, Mexico.

Figure 4. Cont. 


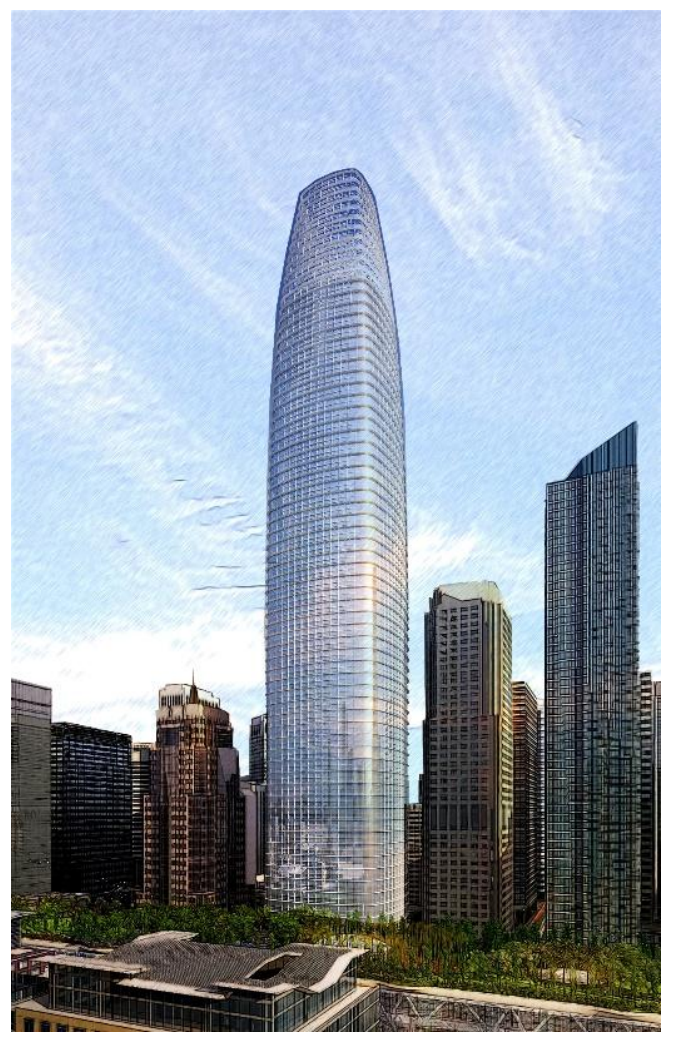

Salesforce Tower, San Francisco, CA.

Figure 4. North America.

\subsection{Aqua Tower}

Designed by Studio Gang, Aqua Tower offers a new sustainability paradigm. Located north of the Millennium Park in Chicago, Aqua is an 81-story, $251 \mathrm{~m}$ (823-ft)-tall mixed-use tower, comprising 15 levels of hotel, 34 levels of rental apartments, and 28 levels of condominiums [14]. Surrounded by a forest of tall buildings, the tower's sculpted form evokes a moving wave with a rippling effect across contours of natural formation. This effect is the result of free cantilevered, undulating balconies stretching outward from 0.6 to $3.7 \mathrm{~m} \mathrm{(2} \mathrm{to} 12 \mathrm{ft}$ ). The layered topography of limestone outcroppings along the Great Lakes region inspired the building's form. The tower's spacious balconies shade the glass and offer a foil to wind pressure- two important concerns for tall buildings. They also allow for residents to enjoy spectacular views of the city while in the outdoor. Ninety percent of Aqua spaces enjoy natural ventilation and sunlight, exceeding the Chicago's minimal requirements by more than 50 percent. Also, architects placed solar glass, which reduces solar heat gain, in the areas where the balcony depth does not protect from the sun. Collectively, the tower utilizes six different types of glass (clear, tinted, reflective, spandrel, translucent, and fitted glass) — to optimize relationships with external environmental conditions. In combination with the balcony handrail design, fritted glass reduces bird-building collision. Consequently, this "topographic" tower evokes a dazzling, new aesthetic direction that is rooted in function. It won the Emporis Skyscraper Award 2009 as the "skyscraper of the year" and received the CTBUH's recognition as a Finalist in its Awards Program in 2010 [12] (Figure 4).

\subsection{VIA 57 WEST}

VIA 57 WEST creates a new sustainable tall building typology, "the courtscraper", as described by BIG founder, Danish architect Bjarke Ingels. The 709-unit residential building forges a hybrid 
model that combines the advantages of the European's courtyard block and the traditional Manhattan high-rise. That is, the building's courtyard offers intimate, dense, greenery spaces that are typically found in European residential courtyards-the communal green space at the epicenter of the block resonates the classic Copenhagen "urban oasis". Simultaneously, the tower embodies the grandeur, airiness, and expansive views found in many Manhattan skyscrapers. To maximize views of the nearby Hudson River, the courtyard block twists three dimensionally—facing the river-by raising one corner of the block and keeping three corners low. In addition to providing uninterrupted views towards the waterfront, the tower's dramatic silhouette minimizes its perceptual impressions of enormity and obstruction and offers height transition between the low-rise buildings placed to the south, and residential towers placed to the north and west of the site. Consequently, VIA's appearance changes dramatically, depending on the viewer's location. That is, from the east, the building appears as a slender spire and from the west; it looks like a skewed pyramid. Collectively, VIA is one-of-a-kind building that twins sustainability with innovative aesthetics. It evokes a visually appealing architecture without sacrificing environmental performance or residential quality. Completed in 2016, it is one of the most recent stunning additions to Manhattan skyline. The building received the 2016 CTBUH's "Best Tall Building in the Americas Award" [14] (Figure 4).

\subsection{Devon Energy Center}

Designed by New Haven-based architect Pickard Chilton, the $170,000 \mathrm{~m}^{2}\left(1,800,000 \mathrm{ft}^{2}\right)$ complex serves as the office home to the company's more than 2000 employees and contractors, and the ground floor of the building is open to the public. The Devon Tower surpassed Chase Tower as the tallest building in Oklahoma City. The 50-story tower's mass is articulated by three wings (forming a triangular base), with each being composed of two sides and a chamfered top, resulting in an elegant form that is well integrated into the neighborhood, lessening its visual impact on the significantly shorter buildings nearby. Viewed from all angles, there is no place where the tower "turns its back" on the neighborhood. Further, the tripartite base facilitates a highly efficient space through a relatively shallow floor plate, which maximizes natural light. The maximization of natural light is also enabled by a $3 \mathrm{~m}(10 \mathrm{ft})$ floor-to-ceiling glazing at the perimeters. The curtain wall consists of a continuous high performance clear glass with a Low-E coating that maximizes daylight and reduces heat gain, and the facades are characterized by a vertical glass blade with a ceramic frit, which is attached to five-foot modules to a stainless-steel-and-aluminum cladding system. Furthermore, the floor plates average $2601 \mathrm{~m}^{2}\left(28,000 \mathrm{ft}^{2}\right)$ in area, accommodating up to 12 full-corner offices that bring natural light deep into the building. Additionally, the building's layout, mass configuration, and all-glass curtain wall facilitate panoramic views of the prairie landscape in the distance [15] (Figure 4).

\subsection{The Bow}

The 58-story Bow office building rises to $238 \mathrm{~m}(779 \mathrm{ft})$ and it is currently the tallest tower in Calgary and the tallest in Canada outside of Toronto. As a bold new landmark on the city's skyline, the $158,000 \mathrm{~m}^{2}\left(1,700,000 \mathrm{ft}^{2}\right)$ project is one of the largest commercial office developments in Canada. The skyscraper is the headquarters for energy giants EnCana (TSX:ECA) and Cenovus (TSX:CVE), among other companies. It was designed by Foster \& Partners and was completed in 2012. The original design proposed that the tower would reach a height of $300 \mathrm{~m}(1000 \mathrm{ft})$. However, due to shadowing concerns, it was lowered to $238 \mathrm{~m}(781 \mathrm{ft})$ [16]. The bow-shaped building provides the greatest perimeter accommodation, creating protected outside public space within the arc, facing south. It also provides an aerodynamic form (with the convex facade positioned against the prevailing wind), mitigating the impact of Calgary's strong wind and decreasing the required structural support for the already efficient diagrid structure. The aerodynamic form, orientation, and diagrid system collectively reduced the required steel by $30 \%$. The diagrid is a large-scale system wherein each triangulated section unifies six stories, resulting in segments that enhance the visual impact of the tower while avoiding a 
monolithic appearance. The CTBUH recognized The Bow as the "Best Tall Building Americas" in the 2013 Awards Program [12] (Figure 4).

\subsection{Manitoba Hydro Place (MHP)}

Manitoba Hydro is a major government owned energy utility (electric and natural gas) in the Province of Manitoba and it is the fourth largest energy utility in Canada. The company wanted to make Manitoba Hydro Tower a leading example for the future of healthy, ecological, and energy efficient office buildings in extreme climates-temperature fluctuates from $-35^{\circ} \mathrm{C}$ to $+34^{\circ} \mathrm{C}\left(-31^{\circ} \mathrm{F}\right.$ to $\left.+95^{\circ} \mathrm{F}\right)$ over the course of the year in Winnipeg. Occupying a full city block in Winnipeg's downtown, it is dubbed the "Open Book" by citizens of Winnipeg because it embraces a triangular shape resembling a capital " $\mathrm{A}$ ". The complex consists of two 18-story twin office towers that sit on a stepped, three-story, street-scaled podium. Each tower contains column-free office spaces and a service core connects the two towers. The towers merge on the north sides, while the south side contains stacked six-story winter gardens, forming the short side of the triangle. The winter gardens feature $24 \mathrm{~m}(78 \mathrm{ft})$-tall waterfalls that humidify or dehumidify air (depending on the season), while also enhancing the aesthetics of the space. The salient feature of the building is a $115 \mathrm{~m}(377 \mathrm{ft})$-tall solar chimney-located at the north elevation and main entrance of Portage Avenue-that provides passive ventilation and presents the building as a new urban icon, giving the building prominence in the city's skyline. The tower is the first large office building in Canada to achieve LEED Platinum Certification from the Canada Green Building Council (CaGBC), the highest certification that is available under the LEED program. The 21-story, $115 \mathrm{~m}$ (377 ft)-tall tower was completed in 2009. The CTBUH recognized Manitoba Hydro Place as the "Best Tall Building Americas" in the 2009 Awards Program [12] (Figure 4).

\subsection{Torre Cube}

Designed by the Catalan architect Carme Pinós, the 16-story, $58 \mathrm{~m}(190 \mathrm{ft})$ tall Torre Cube is a landmark tower in the city of Guadalajara, the capital of Jalisco, Mexico. The tower is in an area of high seismic activity and, therefore, its structure, shape, and geometry have been appropriately designed to withstand earthquakes. Completed in 2005, the tower takes advantage of Guadalajara's mild and sunny climate, bringing natural ventilation and light into the building. Additionally, the building's double skin and central atrium allow for natural ventilation at all time. Furthermore, wooden-latticework along the outer skin of the building reduces solar gain, collectively obviating the need for air conditioning. Nonetheless, the interior receives abundant natural light. This is a unique example of a tall building that relies entirely on natural ventilation and light year-round, which significantly reduces its energy consumption and eliminates the need for cumbersome and expensive HVAC equipment [14] (Figure 4).

\subsection{Salesforce Tower}

Completed in 2018, Salesforce Tower (Transbay Tower) rises $326 \mathrm{~m} \mathrm{(1070} \mathrm{ft)} \mathrm{and} \mathrm{it} \mathrm{is} \mathrm{the} \mathrm{tallest}$ building in San Francisco, surpassing the Transamerica Pyramid Center, previously the city's tallest, by $61 \mathrm{~m}(200 \mathrm{ft})$. Similar to Comcast Center, Transbay Tower embraces the timeless form of the obelisk, exhibiting a slender and tapering shape. The tower's facades are composed of clear glass, pearlescent white horizontals, and vertical accents that gradually taper inward to accentuate the tower's curved glass corners. These rise past the top floor to form a transparent crown that appears to dissolve into the sky. Designed by Pelli Clarke Pelli Architects, the building's skin integrates metal sunshades that reduce solar heat gain while maximizing daylight and external views. It also features high-performance, Low-E glass that reduces cooling loads as well as enhancing the performance of energy and light transmission [14] (Figure 4). 


\section{Discussion}

The aforementioned case studies offer an extensive variety of green design approaches. To facilitate the discussion, this section first summarizes green design features of the examined case studies in Table 1.

The next section proposes a framework to classify the salient green design features, according to major topics, such as structural efficiencies, renewable energy, façade technology, bio-climatic, biomimicry-inspired, and greeneries. These categories also engage additional buildings, not included in the aforementioned case studies.

\subsection{Structural Efficiencies}

\subsubsection{Aerodynamic Forms}

Given the increasing height of skyscrapers, structural engineers are paying more attention to aerodynamic forms and wind. For slender tall buildings, the lateral wind motion that is induced by vortex shedding is a major source of wind-induced excitation. In this phenomenon, as winds hit a building's façade they swirl to adjacent faces creating vortices. These winds break away from the building on one side and then the other, creating what is known as the "von Kármán vortex street" effect. As each vortex breaks away, wind speed increases on the building side, lowering air pressure and increasing pull. Consequently, the building experiences a repetitive side-to-side push caused by the alteration of these vortices [22]. Interestingly, in addition to structural benefits, aerodynamic forms could offer sustainable rewards and improve building's iconicity. Advancements in the aerospace and automobile industries have allowed for the better analysis of aerodynamic forms of tall buildings. In the same manner, digital modeling provides architects with endless design possibilities of aerodynamic forms. It facilitates creating irregular and curvy surfaces that "confuse" and deflect the wind, which consequently reduce the required structural materials. These iterative processes could give architects and engineers opportunities to reach forms that twin structural engineering efficiency with beauty.

For example, the 30 St Mary Axe's aerodynamic form works well with wind, reducing wind stress on the exterior and diminishing the downward wash of turbulent wind gusts (katabatic downward winds) that often disturb pedestrians and activities at the street level. This form also disperses reflected light, thereby further enhancing its environmental effects. The tower's circular form provides 360-degree views of London, with the efficient footprint of the tower $(40 \mathrm{~m} / 131 \mathrm{ft})$ in diameter), maximizing the public space and natural lighting of the ground level. Further, the building's aerodynamic form makes the tower appear less massive than a conventional rectangular block of equivalent size, with its tapered form receding from the eye so as not to overwhelm viewers at the street level.

Norman Foster also applied an aerodynamic form to The Bow in Calgary, mitigating the impact of Calgary's strong wind, and decreasing the required structural support for the already efficient diagrid structure. Other towers that have embraced aerodynamic forms include Wuhan Greenland Center in Wuhan, China; Digital Media City Landmark Tower (unbuilt) in Seoul, South Korea; the Post Office Tower in Bonn, Germany; KfW Headquarters in Frankfurt, Germany; Strata SE1 Tower in London, UK; Devon Energy Center in Oklahoma City, OK; and Salesforce Tower in San Francisco, CA. 
Table 1. Summary of Applied Sustainable Design Features.

\begin{tabular}{|c|c|c|c|c|c|c|c|c|}
\hline$\#$ & Building's Name & Height $\mathrm{m} / \mathrm{f}$ & \# of Stories & Building's Function & Year of Comp & City & Climate * & Prime External Green Features (Building's Envelop) \\
\hline & & & & & & & & Southeast Asia and the Far East \\
\hline 1 & Shanghai Tower & $632 / 2073$ & 128 & Hotel/office & 2015 & Shanghai & $\begin{array}{l}\text { Humid } \\
\text { subtropical }\end{array}$ & $\begin{array}{l}\text { - The tower's twisting and tapering form improves wind } \\
\text { resistance and enhances structural efficiencies. }\end{array}$ \\
\hline 2 & Pearl River Tower & $309 / 1015$ & 71 & Office & 2013 & Guangzhou & $\begin{array}{l}\text { Humid } \\
\text { subtropical }\end{array}$ & $\begin{array}{l}\text { - The tower is sculpted to invite winds into designated slots that } \\
\text { provide pressure relief and hence improves wind resistance. } \\
\text { - Wind turbines are incorporated in the wind slots. }\end{array}$ \\
\hline 3 & $\begin{array}{l}\text { Wuhan Greenland } \\
\text { Center }\end{array}$ & $636 / 2087$ & 126 & Hotel/residential/office & N.A. & Wuhan & $\begin{array}{l}\text { Humid } \\
\text { subtropical }\end{array}$ & $\begin{array}{l}\text { - The tower embraces an aerodynamic form that improves } \\
\text { wind resistance. }\end{array}$ \\
\hline 4 & Menara Mesiniaga & $63 / 207$ & 15 & Office & 1992 & Subang Jaya & $\begin{array}{c}\text { Tropical } \\
\text { rainforest }\end{array}$ & $\begin{array}{l}\text { - A series of vertical plantings, situated along the façade and } \\
\text { "skycourts" that start from a three-story high mound and spiral } \\
\text { to the roofline of the building. } \\
\text { External aluminum fins and louvers are placed on the east and } \\
\text { west facades to provide sun shading. } \\
\text { - The rooftop terrace is covered with a sunroof of trussed steel } \\
\text { and aluminum, which shades and filters light onto the } \\
\text { swimming pool and gymnasium. }\end{array}$ \\
\hline 5 & Oasia Downtown & $191 / 626$ & 27 & Hotel/SOHO & 2016 & Singapore & $\begin{array}{c}\text { Tropical } \\
\text { rainforest }\end{array}$ & $\begin{array}{l}\text { - It boasts a } 750 \text { percent replacement value by employing a } \\
\text { façade of aluminum mesh covered in } 20 \text { species of flowering } \\
\text { vines and creeper plants that provide shade, absorb heat, } \\
\text { and cool and purify the air. }\end{array}$ \\
\hline 6 & $\begin{array}{l}\text { Parkview Green } \\
\text { FangCaoDi }\end{array}$ & $87 / 285$ & $9 \& 18$ & Hotel/office/retail & - & Beijing & $\begin{array}{l}\text { humid } \\
\text { continental }\end{array}$ & $\begin{array}{l}\text { - The building has a mega-slanted roof that regulates airflow } \\
\text { internally and helps to remove snow and rain externally. } \\
\text { - The micro climatic envelope comprises a Texlon ETFE } \\
\text { membrane system of glass and structural steel facades. } \\
\text { - A type of diagrid structure makes the pyramid-like } \\
\text { building outstanding. }\end{array}$ \\
\hline 7 & $\begin{array}{l}\text { ParkRoyal on } \\
\text { Pickering }\end{array}$ & $89 / 292$ & 16 & Hotel & 2013 & Singapore & $\begin{array}{c}\text { Tropical } \\
\text { rainforest }\end{array}$ & $\begin{array}{l}\text { - Excessive greeneries proliferate the tower in balconies, sky } \\
\text { gardens, and terraces. }\end{array}$ \\
\hline 8 & CapitaGreen & $242 / 794$ & 40 & Office & 2014 & Singapore & $\begin{array}{l}\text { Tropical } \\
\text { rainforest }\end{array}$ & $\begin{array}{l}\text { - More than half of the facade is covered with various } \\
\text { flourishing plants and vertical greenery, sky terraces at levels } \\
14 \text { and } 26 \text {, and a sky forest at level } 40 \text {. } \\
\text { Wind scoops are placed on the roof and oriented to the } \\
\text { prevailing winds, which channels fresh cool air via a void at its } \\
\text { central core. }\end{array}$ \\
\hline
\end{tabular}


Table 1. Cont.

\begin{tabular}{|c|c|c|c|c|c|c|c|c|}
\hline$\#$ & Building's Name & Height $\mathbf{m} / \mathbf{f}$ & \# of Stories & Building's Function & Year of Comp & City & Climate* & Prime External Green Features (Building's Envelop) \\
\hline & & & & & & & & The Middle East \\
\hline 9 & $\begin{array}{l}\text { Bahrain World } \\
\text { Trade Center }\end{array}$ & $240 / 787$ & 45 & Office & 2008 & Bahrain & Arid & $\begin{array}{l}\text { - The twin towers are configured to invite wind to three central } \\
\text { wind turbine placed between the two towers vertically. }\end{array}$ \\
\hline 10 & Doha Tower & $238 / 781$ & 46 & Office & 2012 & Doha & Hot desert & $\begin{array}{l}\text { - A modernized mashrabiyya system is applied over the entire } \\
\text { building's envelope, which improves the thermal performance of } \\
\text { the building and reduces glare. }\end{array}$ \\
\hline 11 & Al Bahar Towers & $145 / 476$ & 29 & Office & 2012 & Abu Dhabi & Hot desert & $\begin{array}{l}\text { - A dynamic, modernized mashrabiyya system is designed to open } \\
\text { and close to optimize thermal performance of the building's skin. } \\
\text { It is placed strategically in areas that need shade. }\end{array}$ \\
\hline 12 & O-14 & $106 / 347$ & 24 & Office & 2010 & Dubai & Hot desert & $\begin{array}{l}\text { A concrete, white skeleton is placed one meter before the tower's } \\
\text { glass skin to provide protection from harsh desert sun. It also } \\
\text { provides structural support. The air in the resulting gap moves up } \\
\text { and hence cools the glass skin. }\end{array}$ \\
\hline 13 & Iris Bay & $175 / 574$ & 35 & Office & 2015 & Dubai & Hot desert & $\begin{array}{l}\text { - The building is sculpted to optimize relationship with the sun by } \\
\text { inviting natural daylight and protecting interiors from direct sun. } \\
\text { The configuration also improves natural ventilation. }\end{array}$ \\
\hline 14 & Beirut Terraces & $119 / 392$ & 27 & Residential & 2016 & Beirut & $\begin{array}{l}\text { Hot-summer } \\
\text { Mediterranean }\end{array}$ & $\begin{array}{l}\text { As the name indicates, large terraces wrap around the building, } \\
\text { giving residents to enjoy the outdoor and mild climate of the city. }\end{array}$ \\
\hline \multirow[t]{2}{*}{15} & $\begin{array}{c}\text { National } \\
\text { Commercial Bank }\end{array}$ & $126 / 413$ & 27 & Office & 1987 & Jeddah & Arid & $\begin{array}{l}\text { - The concept of traditional courtyard is modernized and "placed in } \\
\text { the sky" in this high-rise building. Vertical courtyards offer natural } \\
\text { daylight and protect tenants from direct sun. } \\
\text { - In addition, the building's vertical courtyards reduce air } \\
\text { temperatures slightly before the intake air is used by } \\
\text { air-conditioning machinery. } \\
\text { - The thermal mass provided by the opaque wall mitigates the rapid } \\
\text { transference of excessive heat into the building. }\end{array}$ \\
\hline & & & & & & & & Europe \\
\hline 16 & 30 St Mary Axe & $180 / 590$ & 40 & Office & 2004 & London & $\begin{array}{c}\text { Temperate } \\
\text { oceanic }\end{array}$ & $\begin{array}{l}\text { - The building employs an aerodynamic form that improves wind } \\
\text { resistance and structural performance. } \\
\text { - It also employs an efficient steel diagrid structure. }\end{array}$ \\
\hline 17 & Strata SE1 Tower & $148 / 485$ & 43 & Residential & 2010 & London & $\begin{array}{l}\text { Temperate } \\
\text { oceanic }\end{array}$ & $\begin{array}{l}\text { - The building employs an aerodynamic form. } \\
\text { - It incorporates three wind turbines in the roof. }\end{array}$ \\
\hline 18 & Bosco Verticale & $\begin{array}{l}\text { 116/380; } \\
85 / 279\end{array}$ & $27 \& 19$ & Residential & 2014 & Milan & $\begin{array}{l}\text { Humid } \\
\text { subtropical }\end{array}$ & $\begin{array}{l}\text { - Trees and plants are placed in balconies, covering much of the } \\
\text { towers' facades. } \\
\text { - Photovoltaic system. }\end{array}$ \\
\hline
\end{tabular}


Table 1. Cont.

\begin{tabular}{|c|c|c|c|c|c|c|c|c|}
\hline$\#$ & Building's Name & Height $\mathrm{m} / \mathrm{f}$ & \# of Stories & Building's Function & Year of Comp & City & Climate * & Prime External Green Features (Building's Envelop) \\
\hline 19 & Post Office Tower & $163 / 535$ & 41 & Office & 2002 & Bonn & Oceanic & $\begin{array}{l}\text { - The floor plan of the tower consists of two staggered semi-ellipses } \\
\text { (east-west axis) spaced } 7.4 \mathrm{~m}(24 \mathrm{ft}) \text { apart, which create two } \\
\text { separate buildings. This floor plan's arrangement provides } \\
\text { multiple functions including structural, programmatic, } \\
\text { and aesthetic benefits. Dividing the tower's mass into smaller } \\
\text { sections makes it appear lighter, slenderer, and more elegant. }\end{array}$ \\
\hline 20 & $\begin{array}{c}\text { GSW } \\
\text { Headquarters }\end{array}$ & $82 / 267$ & 22 & Office & 1999 & Berlin & $\begin{array}{l}\text { Maritime } \\
\text { temperate }\end{array}$ & $\begin{array}{l}\text { The undesirable east-west orientation that was imposed by the site } \\
\text { was treated by employing a DSF and a thermal flue. } \\
\text { The interstitial space of } 0.9 \mathrm{~m}(3 \mathrm{ft} \text { ) contains colorful shading } \\
\text { devices, a series of vertically pivoting and sliding louvers, } \\
\text { which shut out the unwanted light of the harsh afternoon sun. } \\
\text { These rich colors along with the building's flying roof sculpture } \\
\text { make the GSW Headquarters an instantly recognizable building. }\end{array}$ \\
\hline \multirow[t]{2}{*}{21} & KfW Headquarters & $56 / 184$ & 14 & Office & 2010 & Frankfurt & $\begin{array}{c}\text { Temperate } \\
\text { oceanic }\end{array}$ & $\begin{array}{l}\text { - The DSF's outer skin consists of saw-tooth units where the wider } \\
\text { side is made of fixed single sheet safety glazing, and the narrower } \\
\text { side is made of colored panels. The panel of every other unit } \\
\text { functions as a "ventilation device" that opens to the outside } \\
\text { allowing for natural ventilation. }\end{array}$ \\
\hline & & & & & & & & North America \\
\hline 22 & $\begin{array}{l}\text { Bank of America } \\
\text { (BoA) Tower }\end{array}$ & $366 / 1200$ & 55 & Office & 2009 & $\begin{array}{l}\text { New York } \\
\text { City }\end{array}$ & $\begin{array}{l}\text { Humid } \\
\text { subtropical }\end{array}$ & $\begin{array}{l}\text { - The tower takes on a striking architectural form by innovatively } \\
\text { reviving the traditional grammar (components) of the } \\
\text { skyscraper-the base, shaft, and top. } \\
\text { Its crown is distinguished by a slanted roof while its shaft draws } \\
\text { from the structure of quartz, diffusing light in a crystalline fashion. }\end{array}$ \\
\hline 23 & $\begin{array}{l}\text { New York Times } \\
\text { Tower }\end{array}$ & $318 / 1046$ & 52 & Office & 2007 & $\begin{array}{l}\text { New York } \\
\text { City }\end{array}$ & $\begin{array}{l}\text { Humid } \\
\text { subtropical }\end{array}$ & $\begin{array}{l}\text { - Solar screens of ceramic rods that provide shade. Their vertical } \\
\text { arrangement simulates that of newspaper columns. }\end{array}$ \\
\hline 24 & Aqua Tower & $262 / 859$ & 86 & Residential/hotel & 2009 & Chicago & $\begin{array}{l}\text { Humid } \\
\text { continental }\end{array}$ & $\begin{array}{l}\text { - Balconies contour along the building's façade and vary in shape, } \\
\text { simulating topographic layers of limestone. The resulting } \\
\text { expression is prolific. }\end{array}$ \\
\hline 25 & VIA 57 WEST & $142 / 467$ & 34 & Residential & 2016 & $\begin{array}{l}\text { New York } \\
\text { City }\end{array}$ & $\begin{array}{l}\text { Humid } \\
\text { subtropical }\end{array}$ & $\begin{array}{l}\text { - The rectangular building with a central courtyard is sliced } \\
\text { diagonally to maximize southern exposure. }\end{array}$ \\
\hline
\end{tabular}


Table 1. Cont.

\begin{tabular}{|c|c|c|c|c|c|c|c|c|}
\hline$\#$ & Building's Name & Height m/f & \# of Stories & Building's Function & Year of Comp & City & Climate * & Prime External Green Features (Building's Envelop) \\
\hline 26 & $\begin{array}{l}\text { Devon Energy } \\
\text { Center }\end{array}$ & $257 / 844$ & 50 & Office & 2012 & $\begin{array}{l}\text { Oklahoma } \\
\text { City }\end{array}$ & $\begin{array}{l}\text { Humid } \\
\text { subtropical }\end{array}$ & $\begin{array}{l}\text { - A tripartite base that facilitates a highly efficient space through a } \\
\text { relatively shallow floor plate, which maximizes the provision of } \\
\text { natural light. } \\
\text { - The curtain wall consists of a continuous high performance clear } \\
\text { glass with a Low-E coating that maximizes daylight and reduces } \\
\text { heat gain. The facades are characterized by a vertical glass blade } \\
\text { with a ceramic frit, which is attached to five-foot modules to a } \\
\text { stainless-steel-and-aluminum cladding system. }\end{array}$ \\
\hline 27 & The Bow & $237 / 779$ & 57 & Office & 2012 & Calgary & $\begin{array}{l}\text { Humid } \\
\text { continental }\end{array}$ & $\begin{array}{l}\text { - Convex façade improves wind resistance and maximizes } \\
\text { solar exposure. } \\
\text { - Tiagrid structure optimizes stability and cost saving. } \\
\text { The bow-shaped building provides the greatest perimeter } \\
\text { accommodation, creating protected outside public space within } \\
\text { the arc, facing south. }\end{array}$ \\
\hline 28 & $\begin{array}{l}\text { Manitoba Hydro } \\
\text { Place (MHP) }\end{array}$ & $115 / 377$ & 21 & Office & 2009 & Calgary & $\begin{array}{l}\text { Humid } \\
\text { continental }\end{array}$ & $\begin{array}{l}\text { The salient feature of the building is a } 115 \mathrm{~m}(377 \mathrm{ft}) \text {-tall solar } \\
\text { chimney-located at the north elevation and main entrance of } \\
\text { Portage Avenue- that provides passive ventilation and presents } \\
\text { the building as a new urban icon, giving the building prominence } \\
\text { in the city's skyline. }\end{array}$ \\
\hline 29 & Torre Cube & $58 / 190$ & 16 & Office & 2005 & Guadalajara & $\begin{array}{l}\text { Humid } \\
\text { subtropical }\end{array}$ & $\begin{array}{l}\text { - This is a rare example of a tall building that relies entirely on } \\
\text { natural ventilation and light year-round, which significantly } \\
\text { reduces its energy consumption and eliminates the need for } \\
\text { cumbersome and expensive HVAC equipment. } \\
\text { The building's double skin and central atrium allow for natural } \\
\text { ventilation at all time. } \\
\text { - Wooden-latticework along the outer skin of the building reduces } \\
\text { solar gain. }\end{array}$ \\
\hline 30 & Salesforce tower & $326 / 1070$ & 80 & Office & 2018 & $\begin{array}{c}\text { San } \\
\text { Francisco }\end{array}$ & $\begin{array}{l}\text { Warm-summer } \\
\text { Mediterranean }\end{array}$ & $\begin{array}{l}\text { - The building's skin integrates metal sunshades that reduces solar } \\
\text { heat gain while maximize daylight and external views. } \\
\text { It also features high-performance, low-emissivity glass that } \\
\text { reduces cooling loads as well as enhances the performance of } \\
\text { energy and light transmission. }\end{array}$ \\
\hline
\end{tabular}


Remarkably, architects and engineers have crafted Shanghai Tower's aerodynamic form to resist the typhoon-level winds common to Shanghai. To that end, the form embraces multiple strategies, including asymmetry, tapering, rounded corners, and a reduced floor plate as the tower rises. Testing scenarios and simulation were carried out to simulate typhoon-like conditions, suggesting a 120-degree twist as the optimal rotation for minimizing wind loads. The resulting form reduced the lateral loads of the tower by $24 \%$, saving $\$ 58$ million in building materials. As such, Shanghai Tower's aerodynamic form meets aesthetics, symbolic, and wind engineering purposes simultaneously. It symbolizes China's powerful economic growth and reduces wind impact on the tower concurrently [14].

\subsubsection{Triangular Configurations}

Aerodynamic forms often produce curvilinear surfaces that help to mitigate wind impact. Similarly, if properly designed, triangular configurations contribute to a tall building's stability. Frank Lloyd Wright's design of the proposed Mile High Tower provided an earlier example. Wright sensed that the tripod was the most stable form, given that the pressure of one side is immediately resisted by the adjacent sides. Wright's intuition for the Mile High Tower's form was correct. Another early example of a triangular form was the United States (U.S.) Steel Building in Pittsburgh, Pennsylvania.

The tripod-like floor plan has been employed by architect Adrian Smith in prominent buildings, including the $828 \mathrm{~m}(2717 \mathrm{ft})$ Burj Khalifa, the world's tallest building, in Dubai, UAE, and the one-kilometer Jeddah Tower, the world's next tallest, in Jeddah, Saudi Arabia, to be completed in 2020. In addition, Smith applied tripod design to Wuhan Greenland Center. Further, the 51-story Devon Energy Center employs a triangular form.

\subsubsection{Braced, Diagrid Systems, and Exoskeleton}

Given the external nature of these structural systems, they can visually communicate the inherent structural logic of a building while also serving as a medium for artistic effect. Viewed in this light, the visual appeal of these systems can be enhanced to give a tower a more distinct urban identity. This entails the creation of structural elements that are aesthetically pleasing, geometrically coherent, and that demonstrate dexterity of application in regards to a building's composition, while also respecting the laws of physics and mechanics. In this fashion, an artistic approach can exhibit structural systems as not just purely rational features that enable the construction of tall buildings, but as important visual components that afford opportunities for creative expression.

An early system that was used to support the lateral loads of tall buildings is the braced frame, which has historically used various types of bracing elements, such as X-braces, K-braces, Chevron braces, and eccentric braces, to create distinct structural expressions. These different types of bracing are used to satisfy the criteria determined by building's height, slenderness, architectural program, and seismic and wind load conditions in a geographic location. However, in recent years, the diagrid (diagonal grid) structural system has become increasingly popular. A diagrid system consists of series of triangles and horizontal rings of beams, which provide the structure support against gravity and lateral forces, while also making a building stiffer and often lighter than a traditional high-rise. Diagrids are usually composed of steel, because of its high strength and the ability to resist both tensile and compressive forces. The diagrid can suffer from problems of implementation due to its complicated steel joints, but recent advances in joint detailing and prefabrication are helping to address this issue. Due to their triangular configuration, diagrids can efficiently carry the shear and moment caused by lateral loads and gravity.

In regards to structural performance, both braced and diagrid systems are effective at carrying the large lateral loads of tall buildings given their three-dimensional tubular behavior by virtue of their being exterior systems. The braced tube system tends to be more efficient than the diagrid system for ultra-tall buildings with large height-to-width aspect ratios. However, when compared to braces, as alluded to before, the diagrid elements are lighter and less obtrusive. Additionally, diagrids possess greater structural flexibility than bracing systems given that diagrids can be configured, with some 
desirable adjustment in the modules and angle(s) of the diagonals, to meet the architectural and structural requirements. The angles of the diagrid can be adjusted to optimize structural performance, offering more possibilities of structural expression as a result.

It should not be forgotten that the bracing systems of many early tall buildings were antecedent to the diagrid. For example, Fazlur Khan's X-braced John Hancock Center is considered to be a major milestone in the development of braced systems, serving as inspiration for later diagrid designs. However, in the 1980s, it was Norman Foster who more directly popularized the diagrid system, proposing that the Humana Headquarters should implement this structural typology [14]. In the 2000s, Foster successfully employed the diagrid system in several buildings, including London's iconic $30 \mathrm{St}$ Mary Axe (2004) and New York's Hearst Tower (2006) and Calgary's The Bow (2010). 30 St Mary Axe employs an efficient steel diagrid structure comprised of triangular diagonal support beams, obviating the need for large corner columns and providing a better distribution of weight loads. The diagrid system reduced the structural steel that is normally required for a building of this size by $21 \%$ [23,24]. Norman Foster also applied a diagrid system to The Bow in Calgary, mitigating the impact of Calgary's strong wind, and decreasing the required structural support. The aerodynamic form, orientation, and diagrid system collectively reduced the required steel by $30 \%$. The employed diagrid system is of a large-scale wherein each triangulated section unifies six stories, resulting in segments, which enhance the visual impact of the tower while avoiding a monolithic appearance [25].

Earlier, Norman Foster applied a diagrid system to Hearst Tower in New York City. Completed in 2006, it received the 10 Year Award from the CTBUH, acknowledging its sustainable performance, global impact on tall buildings' design and industry, and respect for the built heritage. Foster placed the tower atop the hollowed shell of a 1928 landmark office building. Its unique diagrid structure also saved 2000 tons of steel and used $26 \%$ less energy than a building that is constructed to normal code. Ninety percent of utilized steel was made from recycled materials [26]. Further, developers imported merely $10 \%$ of all its materials, reducing the cost and carbon emissions. Likewise, the 103-story, $439 \mathrm{~m}$ (1439 ft) Guangzhou International Finance Center in Guangzhou, Guangdong, China, has applied a similar diagrid system using an aerodynamic profile $[27,28]$. In addition to being structurally efficient, these buildings are also iconic. These towers are, in many ways, poster-children for the diagrid system, popularizing the technique and making it more palatable for the tall building industry as a whole [29].

Similar to the case of braced and diagrid systems, architects and engineers have employed exoskeletons in tall buildings for providing structural stability and facilitating free-column interior spaces. In addition, exoskeletons evoke unique structural expressions. Further, the creative design of exoskeletons has offered new sustainable benefits, such as shading the façade and fostering natural ventilation. For the example, the exoskeleton of $\mathrm{O}-14$ Tower stands $1 \mathrm{~m}(3 \mathrm{ft})$ away from the inner glass-walled enclosure. The space between the exoskeleton and the building's glass surface produces a chimney effect causing hot air to rise, and hence creating an efficient passive cooling system. O-14's exoskeleton with curvaceous, white color evoke monumental and monolithic exterior. With swerving contours, the concrete shell is perforated by 1326 openings of varying sizes that were positioned through a complex and "random" pattern, creating a lace-like effect on the building's facade. Architecturally, the varying openings seek to attenuate the monotony of the external facade. They also provide an ever-changing sense of interior space through a fascinating interplay of natural light and shade. In addition to providing architectural and aesthetic quality, the tower's shell serves as the prime structural component. It offers an efficient exoskeleton that frees the core from the burden of lateral forces and it creates a column-free, spacious interior of about $557 \mathrm{~m}^{2}\left(6000 \mathrm{ft}^{2}\right)$ [30]. The shell is organized in an efficient diagrid pattern that maintains the required structural support by adding material where necessary and taking away where possible. The required structural effectiveness of the shell was achieved by balancing material strength and aperture size, that is, larger openings received greater support through changes in the concrete mixture. Overall, O-14 Tower's exoskeleton possesses a unique sculptural quality that expresses sublimity and monumentality [31]. 
Similar to Dubai's O-14 Tower, the COR Tower in Miami (unbuilt) features an innovative hyper-efficient exoskeleton that balances the transparency of the recessed glass curtain wall. This exoskeleton also provides insulation, shading, and natural cooling for terraces. The $25 \mathrm{~cm}$ (10 in) exoskeleton provides structural functionality and it serves as solar screens providing light, air, and external views. The space between the exoskeleton and the building's glass surface also produces a chimney effect causing hot air to rise, and hence creating an efficient passive cooling system. The tower also integrates environmental technologies by incorporating rooftop wind turbines. As such, COR Tower creates a unique interplay between structural engineering, environmentally friendly design, architecture, and ecology. Finally, recent projects, such as Oasia Downtown, use the exoskeleton as a place for plants to grow and ascend the height of tall buildings [15].

\subsection{Bio-Climatic Design}

Ken Yeang has applied bioclimatic design principles to the high-rise tower, emphasizing passive measures [32]. He has sought to find ecologically benign ways to make built forms "greener" and more humane. As Yeang explains, "climate provides designers with a legitimate starting point for architectural expression in the endeavor to design in relation to place, because climate is one of the dominant determinants of the local inhabitants' lifestyle and the landscape's ecology" ([33], p. 12). Menara Maisgani offers one of the best examples of this design approach. The building utilizing several passive design strategies. It places the building's core off-center on the east side of the facade to shield the building from the direct rays of the "hot" sun. Made of reinforced concrete, the core provides thermal insulation, and functions as a "heat sink" that re-radiates absorbed heat during the day into the interiors at night. The core area contains elevators, washrooms, and other services, relying on natural ventilation instead of mechanical systems of heating and cooling. The design supplies natural light and views to the outside via windows, and fire escape stairways are unenclosed. Furthermore, windows facing the hot sides of the building (east and west facades) are recessed and contain protruding external aluminum sunscreens to reduce solar heat gain. These solar shading devices are effective because, at the equator, the Malaysian sun enjoys a high path in the sky. A slight protrusion of the facade substantially blocks the sun's rays, providing significant shading. Sky gardens that have been carved out of the east and west facades provide additional shade. Areas of the facades that do not have direct solar insulation (the south and north facades) contain unshielded curtain-walled glazing to maximize natural light and external views [33]. Operable curtain walls lie flush to these facades. Sky gardens are accessible through sliding doors, which also assist in providing natural ventilation. The circular plan facilitates natural lights to office spaces, and functions that require less light are located away from the perimeter.

Similarly, the Commerzbank in Frankfort uses an innovative "Klimafassade" to facilitate natural ventilation. Translated literally from the German as the "climate facade", the "Klimafassade" is a custom-made double skin system that mediates the weather between the interior and exterior of the building. The outer skin comprises a solid pane of skin due to the protruded aerofoil sections. The inner skin comprises a Low-E double-glazed unit that is bottom hinged and opens inwards at the top to a maximum of 15 degrees. The $165 \mathrm{~mm}$ (6.5 in) ventilation cavity between the two skins houses a motorized $50 \mathrm{~mm}$ ( 2 in) venetian blind that shades and deflects solar rays [14]. The outer skin contains slots through which fresh air can enter the cavity between the layers. Cavities contain special aerodynamic transoms that minimize the noise that is generated by air movement within. In the winter, these double facades act as a thermal barrier, allowing for solar penetration, and in the summer, these blinds provide solar control to prevent overheating. The double skin also provides acoustic protection and heats fresh air before it vents into the building. Building tenants can also open office windows on the atrium side for natural ventilation, with plants that are in the sky gardens supplying oxygen. In the wintertime, the building system shuts the sky gardens' windows to trap heat; it reopens them during warm times to let in desirable breezes. In both circumstances, warm air rises and through the negative pressure on the leeward face of the building as the air moves across the exits, a process 
that removes stale air from the interior [15]. Natural ventilation provides a healthier environment for both occupants and plants that proliferate throughout the building, including the sky gardens.

Another interesting example that addressed climate considerations is Torre Cube. The tower's design takes advantage of Mexico's mild and sunny climate to bring in natural ventilation and light. The building's double skin and central atrium allow for complete natural ventilation, while the wooden-latticework placed in its outer skin reduces solar gain collectively obviating the need for air conditioning.

It is worth noting that, arguably, the first bio-climatic tower to break away from the modernist's steel-and-glass box (see, for example, Mies van der Rohe's skyscrapers in Chicago and New York City built in the 1950s) and that provided passive measures for sustainable design, is Frank Lloyd Wright's Price Tower, completed in 1956 in Bartlesville, Oklahoma, USA. Price Tower employs opaque concrete walls punctuated with windows to create a greater thermal mass by reducing solar gain and insulating against the extremes of the local climate. Additionally, the tower uses louvers and fins to control solar gain and light. Its interior spaces receive natural light and ventilation, while its terraces are full of plants, creating seamless connections between indoor and outdoor environments [31].

\subsection{Vertical Landscaping}

Throughout history, architects have claimed to connect their designs with nature. For example, Frank Lloyd Wright, Rudolf Schindler and Richard Neutra all strove to ensure a fluid relationship between indoor and outdoor spaces, human-made, and nature-made environments. In recent years, however, vertical landscaping has been promoted as a feature of bio-climatic, sustainable, or green design. This model initially followed the work of Ken Yeang who advocated "biophilic urbanism", where the city and buildings integrate flora and fauna to promote the innately emotional affiliation of human beings to other living organisms. Yeang contended that we should build our cities by using organic, soft, and natural materials, as opposed to hard and rigid, to address environmental issue of air pollution, urban heat island (UHI), and climate change. He looked into designing the high-rise typology in the 1990s as "vertical green urbanism" and stressed improving the ecological linkages between a building and its surrounding landscape. Indeed, there is a growing recognition of the healing power of nature, and by creating physical "ecological" linkages, we foster connectivity, interaction, and mobility of a wider range of species. In the context of tall buildings, Yeang has promoted the notion of vertical landscaping to facilitate these ecological linkages [33].

From a sustainability perspective, vertical landscaping is desirable because it offers a plethora of benefits, including:

- Improving the environmental health of indoor and outdoor spaces by producing oxygen, filtering polluted air, dust, and reducing urban noise, thereby improving people's comfort and productivity: A $5 \mathrm{~m}$ diameter canopy or $40 \mathrm{~m}^{2}$ of a vegetated wall covered with dense planting can produce the yearly oxygen requirement for one person $[16,17]$. Also, plants sequester carbon from the atmosphere.

- Enhancing aesthetics and offering a local, vernacular touch when indigenous plants are used.

- Improving habitat resilience and species survival.

- Bringing nature closer to the cities and softening their "urban jungle" effect.

- Increasing biodiversity by attracting species such as birds, butterflies, snails, crickets, and tree frogs.

- Reducing stress levels of individuals exposed to greeneries.

- Potentially, providing an agricultural source (see next section).

- Protecting from graffiti and vandalism.

- Protecting the building from the solar load and hence reducing required energy to cool the building during summer time and reducing carbon emission.

- These combined factors reduce the UHI effect and help to combat climate change. 
Consequently, architects and planners increasingly integrate vertical landscaping in tall buildings. Leaders of this trend include Stefano Borie, Vincent Callebaut, Jared Moore, Jean Novel, Yansong Ma, Emilio Ambasz, and Milroy Perera, among others. Remarkably, botanist and garden designer Patrick Blanc has influenced this design direction. The plant and tree-covered towers trend is spreading worldwide, creating a new architectural design paradigm that responds to environmental problems and climate change while offering exciting aesthetics. As such, today, green roofs, sky gardens, sky courts, terraces, and vertical landscaping are among the copious greenery schemes of eco-design. In the aforementioned case studies, we find that these concepts prevail in Menara Mesiniaga, ParkRoyal on Pickering, CapitaGreen, Bosco Verticale, and Oasia Hotel Downtown. Other examples include The Met, Newton Suites, Antilia Tower, One Central Park, ACROS Fukuoka, and Tao Zhu Yin Yuan. Further, several proposed towers follow the same design scheme, including La Tour des Cèdres, Tokyo-Nara Tower, EDITT Tower (unbuilt), Sky Village, New York Tower, and Vertical Park.

The hanging garden skyscraper organizes greeneries into gardens at various levels with vertical landscaping as connectors. For example, the Antilia Tower in Mumbai employs hanging gardens that are connected with "living walls" or vertical gardens that climb to the 40th floor. The various floor plans encompass a variety of garden tiers, terraces, waterfalls, and ponds. Also, the proposed New York Tower by Daniel Libeskind features a series of sky gardens at different heights cut from a façade that provides enclosed green space and terraced balconies.

The design of the proposed Vertical Park in Mexico City resonates the hanging garden. It may compensate for the lack of urban green space, particularly in dense areas where land is scarce and expensive. The project intends to infuse the city with much-needed green space by employing sky-gardens for living and working. The Vertical Park provides a space that can be used both publicly and privately, and that also collects water and solar energy.

Interestingly, the proposed Gwanggyo Power Center integrates vertical parks that contain plantations with box hedges placed around terraces. The collective image creates a strong, recognizable, and cohesive vertical park. The park will provide pleasure to the center's tenants and the public, while also reducing energy consumption by supplying natural ventilation and daylight. Similarly, the proposed Mile High Eco-Skyscraper's design maintains that public parks spread out on the vertical plane. These parks are open to the outdoors (not glazed) and are large enough in scale to be visible from far away. The overall composition of these vertical pocket parks evokes an organic feel to the tower.

On the issues of maintenance, towers that incorporate trees and vegetation require significant maintenance and crews of special expertise and skills, rarely to find. As expressed by Richard Hassell this building typology requires a team of flying gardeners; a pool of laborers who are both Spiderman and gardeners. Over time, living and constantly growing vegetation may threaten façade's integrity. Any required repair at higher altitudes entails higher costs and troubles. Further, integrated vegetation may invite undesirable insects and even snakes that would render these buildings unsafe and undesirable human habitats.

\subsubsection{Vertical Courtyards}

Closely related to vertical landscaping is vertical courtyards or skydecks. As described earlier, in addition to environmental benefits, vertical landscaping masks hard-looking building materials, such as steel and concrete, by adding a soft green layer. Vertical courtyards underscore vertical landscaping by adding "depth". That is, vertical courtyards create a greater visual impact on building's appearance by carving out significant volumes. These elements not only offer greeneries but also often facilitate natural ventilation and provide outdoor spaces that support social life in the sky. Examples of buildings that employed vertical courtyards include Oasia Downtown, National Commercial Bank, VIA 57 WEST, and Torre Cube. 


\subsubsection{The Vertical Farm}

With a burgeoning global population that has created an ever-growing need for increased food production and housing, architects are searching for sustainable solutions that will prevent further sprawl while supplying fresh food to urban residents. This could be achieved through vertical farming in urban settings. Vertical farms could be integrated into skyscrapers as another mixed-use element, along with housing, recreation, work, and tourism. In this way, skyscrapers of the future may become small, self-sufficient cities, complete with on-site energy production and connections to mass-transit, resulting in reduced carbon footprints for both building and residents. Vertical farming would involve exploring innovative sustainable solutions to urban crises and the formation of new relationships among architects, engineers, farmers, and local communities [34].

\subsubsection{Balconies and Terraces}

Certainly, balconies are not new design features of tall buildings, particularly residential ones. In this regard, Rem Koolhaas explains: "Without the balcony, the history of the world would have looked completely different" [35]. Indeed, balconies play functional roles by supplying an outdoor space that residents can use for sitting and relaxing, enjoying views and fresh air, and drying clothes. In addition, balconies could be utilized for incorporating plants and even trees, as explained in a previous section on vertical landscaping. This technique allows for weaving nature in high-rises. However, a new prevailing trend suggests balconies of intriguing forms that drastically affect the resulting form of tall buildings by introducing fresh morphological expressions. In a recent article titled "How architects are changing high-rise living with amazing balconies that stand out in more ways than one" Christopher DeWolf elaborates on this notion [36]. Advances in structural engineering allow constructing larger and deeper balconies and terraces of various forms, resulting in sculptural quality.

Aqua Tower by Studio Gang is an exemplary project of this trend. It integrates balconies of various shapes and sizes, engendering an undulating form of a "topographic expression". Studio Gang builds on this design technique to produce exciting forms, as seen in City Hyde Park Chicago, completed in 2016. Other projects by Studio Gang that embrace this design technique include a proposal for a 40-story residential Folsom Tower in San Francisco. Jeanne Gang commented on this building by stating, "What I like about tall buildings (aesthetically) is what you do with the height, the incremental moves along the way ... .It's not just the extrusion of a single form from bottom to top" [37]. Jeanne Gang proposes also a 14-story building in Miami with varying shapes of balconies resulting in a choppy, prismatic tower. She explained that her design serves as "contemporary reinterpretation of a "Florida room"” [38].

One interesting example that follows this design trend is the 46-story Regalia Condominium Tower in Sunny Isles Florida by Arquitectonic. It integrates undulating verandas to recall the adjacent ocean waves. Bernardo Fort-Brescia, the founding partner of Arquitectonica, explains that these balconies serve functional needs. He states, "Its transparent surfaces connect inside and outside, linking the occupants with the surrounding environment. Its orthogonal geometry creates elegant, serene, classical, zen-like spaces. Each floor is wrapped by a sensuously undulating terrace. The resulting walk-around veranda protects the glass surfaces from the sun, as in traditional Florida homes. It is this veranda that shapes the architecture" [39]. The Wave Tower in Gold Cost, Australia embraces a similar design. Likewise, Beirut Terraces, as the name indicates, integrates abundance of large terraces of various sizes and design, creating dynamic visual expressions.

While manipulating the design of balconies is likely to result in new morphological expressions, it may risk losing their essential functionality. For example, varying shapes may result in dead spaces, i.e., un-utilized spaces because of being too small. For example, Aqua Tower's balconies have odd and shallow areas that render them unusable. These shallow areas also cancel the shading benefits of balconies. In the example of Aqua Tower, facades under shallow balconies had to use different type of glass to reflect sun and heat. Further, with greater heights, wind velocity increases dramatically, 
making balconies uncomfortable places. Therefore, if balconies were integrated in a tall building, they should respect and support climatic considerations and not follow a preconceived form per se.

\subsection{Solar Shading Devices}

Balconies and terraces offer multiple functions, including shading benefits, as discussed above. However, some buildings, such as office buildings, may not need balconies. As such, shading devices could be employed. Principally, the glare caused by glass is a significant problem for both the interior and exterior of a building. Glare occurs through an extreme contrast between bright areas that receive direct sunlight and adjacent areas of darkness. Inside a building, glare often occurs in areas close to windows that receive a large amount of sunlight, for "usually a single south-facing window can illuminate up to 20 to 100 times its unit area" [19]. Such a large amount of light may result in glare if concentrated on a small area. Additionally, unwanted heat gain occurs when sunlight enters the building on warm days, with local climate and facade orientation being the main determinants of sun control in regard to heat gain. In the last decades, the world has witnessed a significant high-rise development that embraces Western models of all-glass curtain walls, ignoring local climatic conditions. In this regard, solar shading devices play important functional roles. For example, cooling all-glass buildings is costly, both financially and environmentally, particularly in hot climates like that of Abu Dhabi, where intense sunlight causes temperatures to rise frequently above $38^{\circ} \mathrm{C}\left(100^{\circ} \mathrm{F}\right)$. In addition to functional roles, solar shading devices may offer interesting visual expressions, as follows [15].

\subsubsection{Static}

"Static" solar shading devices can address problems of glare as well as control issues of heat gain and loss. They come in different forms and shapes (e.g., sunshades, light shelves, blinds, fins, overhangs, horizontal louvers, vertical louvers, or shade cloth). These elements may have direct impact on a building's visual expression. For example, fins can reinforce the vertical expression, while cantilevers stress a building's horizontality.

Architects could be creative in introducing new forms of shading devices. For example, New York Times Tower integrates in its glazed facade a brise soleil consisting of 186,000 ceramic rods that link to a dimmable lighting system [14]. Yet, the screens of ceramic rods that float in front of the clear glass curtain wall are the building's signature. Renzo Piano, the architect of the building, has called the screens a "suncoat" - as opposed to a raincoat - that cuts the transmission of light and heat into the interior, thereby permitting the use of clear, rather than tinted glass. Interestingly, the vertical arrangement of the rods resembles lines of newspaper columns, a fitting visual expression to the function of the building, producing newspapers. Menara Mesiniaga integrates repetitive curvilinear aluminum sunscreens that give the building a unique visual expression. Finally, Doha Tower by Jean Nouvel creatively modernizes mashrabiyya. It offers a new interpretation of the traditional mashrabiyya by varying its density in response to solar orientation.

\subsubsection{Dynamic}

"Dynamic" solar shading devices have the opportunity to offer a better response to solar exposure and "dynamic" visual expressions. Most notably, Al Bahar Towers have modernized the traditional mashrabiyya. Unlike the static and two-dimensional traditional mashrabiyya, Al-Bahar's mashrabiyya is dynamic and three-dimensional. In response to direct sunlight, the mashrabiyya can unfold to cover the facade, and when the sun is obscured, it can close to allow for daylight penetration. Geometrically, the mashrabiyya system follows a hexagonal pattern that simulates traditional Arabic-Islamic design. As the mashrabiyya system opens and closes, the towers always change their appearance, stimulating intriguing aesthetics. Parametric and algorithmic modeling has been used to optimize the mashrabiyya location on the facade, precluding the use of dark tinted glass, which would permanently restrict incoming light. The system provides a 50\% reduction in solar gain, resulting in decreased energy consumption and $\mathrm{CO}_{2}$ emissions [15]. 
In the case of KfW Headquarters, the polychromy of the facade's narrow ventilation flaps with different hues of red, blue, and green, enhance the building's visual aesthetics. The ventilation panels are computer controlled via the BMS, guided by environmental sensors that are placed on the DSF. The system computes when and how much the exterior panels should open to maintain a constant and even pressure within the ring, with airflow being regulated not to exceed $6 \mathrm{~m} / \mathrm{s}(20 \mathrm{ft} / \mathrm{s})$. As such, the color composition is dynamic, that is, the changing position and setting of the ventilation panels result in a vibrant play of color across the facade. Finally, the biomimicry-inspired Cactus Building in Doha, Qatar (unbuilt) provides an innovative example of how eco-design can mimic nature. The building's skin is sensitive to Qatar's hot climate and features smart shades that open and close in response to heat, thereby mimicking the natural functions of a cactus [14].

\subsection{Renewable Energy}

Architects, environmentalists, politicians, among others, are increasingly interested in exploring ways to harness renewable energy sources that reduce reliance on fossil fuels. Wind, solar, biomass, geothermal, and hydroelectricity energy technologies generate electricity with no combustion emissions. Gradually, the costs of renewable energy are becoming much more competitive with fossil fuels. Future tall buildings may strive to become "zero energy" or even "positive energy", so that in a year they may generate as much or more energy than they consume. In this latter case, the extra supply may be sold off to the city's power grid [16].

\subsubsection{Wind Turbines}

Integrating wind turbines in tall buildings may result in one of the boldest visual expression of sustainability. Functionally, wind is a renewable energy resource that can be utilized, particularly at the higher altitudes of tall buildings where wind speed is considerable. Tall buildings can be shaped to funnel these winds into zones that contain wind turbines without having a negative effect on the structure, its surroundings, and the occupants. Providing this structural profile, wind speed is amplified to produce more energy. In the case of Bahrain Towers, Pearl River Tower, and Anara Tower, among others, their shapes and forms considered harnessing wind energy.

The Bahrain Towers, in particular, were shaped to take advantage of the local prevailing winds by funneling them into three large wind turbines. Using laboratory wind-tunnel testing, Atkins was able to define the building's tapering and angles to keep the wind source consistently strong for all three propellers. The building's shape ensures that any wind coming at a $45^{\circ}$ angle to either side will create a wind flow that intersects perpendicularly with the turbines. However, for practical reasons of mechanical malfunctioning and noise generation, these turbines were closed shut by building management. As a result, these turbines stand still [16].

The Strata SE1 Tower in London also incorporates three $9 \mathrm{~m}(30 \mathrm{ft})$ wind turbines on the rooftop, which give the tower a distinctly "green" identity. In the case of Pearl River Tower in China, the tower was shaped to funnel the wind into two major openings in the building that contain wind turbines. Its shape also reduces lateral wind pressure. Originally, the tower was designed to be "zero-energy" (producing as much energy as it consumes). However, due to local regulations and codes, the design has been compromised, and the building is no longer energy self-sufficient [16]. Consequently, the economic efficiency of wind turbines continues to be questionable.

\subsubsection{Photovoltaic}

Photovoltaic panels are likely to have a lesser visual impact on buildings than that by wind turbines. However, similar to wind turbines, their efficiencies continue to be questionable. Stated differently, although tall buildings feature large facades that give the promise of employing photovoltaic (PV) panels at a mega scale, the output of PV has been marginal. For example, Heron Tower in London features a facade-mounted solar PV array; it generates merely $2.5 \%$ of the building 
electricity demand. This is because tall buildings are energy hogs and PV technology continues to be inefficient. In addition, London's predominantly cloudy weather makes PV the least productive [14].

\section{Conclusions}

The 21st Century city is increasingly vertical. Many cities around the world are embracing or re-embracing the tall building as a major building typology and are attempting to make it sustainable. It is important to pay attention to the functional performance of this building typology as well as its impact on the visual aesthetics. This paper mapped out the "sustainable" design features that may affect tall building's visual expressions. It examined dozens of projects that employed a wide-range of design approaches. Yet, all these projects are widely recognized for design excellence, and have received awards from major tall building organizations. The examination has focused on identifying sustainable design features that grant the building clear identity and make it an iconic landmark. This paper, therefore, synthesizes the concepts of sustainable design and creative artistry to facilitate a better understanding of the aesthetic developments in skyscrapers worldwide. The ultimate goal is to empower architects and engineers with design choices that result in sustainable and beautiful buildings.

The examined examples have embraced sustainable design features and technologies in different ways and to greater and lesser degrees. Some are boldly iconic, and others are subtly iconic. As such, they provide a mix of examples, yet they share two prime qualities of being green and attractive. In numerous cases, there have been sound rationales for adopting or refusing eco-design ideas. We find examples of skyscrapers that are shaped to harness wind power, others that shunt wind force to decrease lateral loads and others that have employed articulated exoskeletons to balance solar gain while providing natural ventilation. Certainly, these examples point to a new path for skyscrapers that departs from the plain, monolithic vertical extrusions of the orthogonal, air-conditioned box.

Hybrid designs embrace an eclectic approach that incorporates selected green features without adhering to any one specific theme. This option is attractive and common, providing architects with the freedom to chart their design by navigating a myriad of green options. Because some green design features are costly, the hybrid approach may allow clients and architects to work together to optimize their choices. Hence, architects need not morph, twist, or tweak their buildings to fit a particular green design theme, such as the organic or bionic. Instead, they may employ a wide-spectrum of forms that simultaneously incorporate a plethora of green design features. This paper supports and guides efforts seeking a hybrid/eclectic design approach. A summary of these design approaches is provided in Table 2.

Overall, the plants and trees-covered tower offers a promising sustainable model. It represents a paradigm shift from "garden city" to "city in a garden". This subtle but important change emphasizes the desire for a more immersive nature and a view of urban life where nature is not the "icing on the cake" element or a lonely landscaping project, rather the predominant, integrative, and ubiquitous feature of the city. Plants and trees-covered towers support biodiversity and promote flora and fauna. They offer "quiet spaces", where tenants can enjoy peaceful contemplation, attractive views, and fresh air. In these towers, people will be able to listen to sounds of many bird species, crickets, tree frogs, katydids, and grasshoppers, while watching snails and butterflies traveling across plants. In addition to enhancing "soundscape", these towers have the potential to enhance the "smellscape" of the city. Indeed, some vegetation provokes wonderful and attractive smell. The implementation of this model could be for the entire building or part of it, for example, a parking structure [14].

Notably, Singapore has instated a citywide landscape replacement policy that mandates a minimum of one-to-one replacement of ground-level nature with vertical green elements-this, in turn, has promoted plants and trees-covered towers. What makes this possible is that Singapore has a tropical environment where growing trees and plants is relatively easier. As we have seen in this paper, ParkRoyal on Pickering and CapitaGreen are exemplary projects of this trend. These buildings have embraced genuine concepts and green design principles that resulted in interesting and eye-catching tall buildings. Nevertheless, it is important to note that ensuring a robust maintenance of greeneries is 
essential to sustain the intended environmental benefits. Buildings' owners should keep out unwanted insects and animals [19].

A building's design and appearance should be determined by the collaborative decisions of the interdisciplinary team, and discretion should be used in regards to the level of boldness or the subtlety expression of sustainable design elements. Through an iterative process, and with the help of powerful computer modeling tools, design teams may decide on how specific elements, such as aerodynamic forms, structural systems (braced, diagrid, exoskeleton), vertical landscaping, renewable energy features, and shading devices can be applied to improve function and aesthetics simultaneously. Other sub-variables, such as shading, decoration, color, curtain walls, patterns, scale, structural details, lighting systems, etc. can be examined as well. In the author's opinion, complex and iconic forms should not be used just for their novelty or fashion of a time, but also keeping in mind their cost effectiveness and rational quality that will transcend and pass the test of time.

A beautiful, sustainable architecture may have the potential to restore the original meaning of iconicity as a characterization of outstanding and timeless architecture. The forms of eco-iconic buildings stem mainly from green design, yet they are still attractive. Frank Lloyd Wright, through the influences of Louis Sullivan, once famously wrote that beautiful forms could only be created after functional needs have been satisfied. Perhaps, it is time to re-appropriate the word "iconic" for the purpose that it was originally intended; as a way of recognizing well-established architecture, which is beautiful, functional, and fitting. In the 21st Century, it is possible to create beautiful forms that embrace creative green design ideas, principles, and technologies. It is possible to twin sustainability with innovative aesthetics in designing tall buildings.

Although this paper advocates embracing sustainable design, it acknowledges that greenwashing is prevalent. Cities' "green" agendas have been "hijacked" by industries who wish to take advantage of the new trend by converting sustainable mission into money-grubbing businesses. Industries propagate the notion that new technologies offer superior "sustainable" benefits. Stephen Mouzon reflects on this issue by stating: "Today, most discussions on sustainability focus on 'gizmo green,' which is the proposition that we can achieve sustainability simply by using better equipment and better materials" [40]. Surely, integrating "smart" technology and "green" machines into our daily life is important; nevertheless, "this is only a small part of the whole equation. Focusing on gizmo green misses the big picture entirely", according to Mouzon [40].

Stephen Mouzon also offers in his recent book The Original Green: Unlocking the Mystery of True Sustainability crucial remarks on the importance of doing less with more [41]. He explains that sustainable design could be achieved without relying on costly technologies. He states, "In the current world of green and sustainable design, so much weight is put on technology; the adding of solar power, high tech glass, qualifying for LEED. It is all about ADDING things" [42]. The main lesson we may learn from Mouzon' research is how well one can do with less by sharing resources and becoming less consumptive of finite resources and more efficient in everything we do. Interestingly, "doing well with less" echoes "less is more" motto that was embraced by Modernist architects, for example, Ludwig Mies van der Rohe, whose work has a profound impact on tall buildings development.

Overall, this review paper confirms that the path to creating sustainable vertical city is arduous and long. Present practices are far from the age of the sustainable skyscraper city. Researchers need to conduct significant work at the planning, architectural, and engineering levels in the design, construction, and integration of the skyscraper into cities. Management of the building, evaluation of its performance and assessment of tenant satisfaction are also essential components to achieving more sustainable skyscrapers. "Greenwashing" or "bogus sustainability" is becoming mainstream criticisms of sustainable tall buildings. We continue to lack a solid grasp of the full implications-the physiological, psychological, social, economic, and environmental implications-of vertical living, which entail cramming greater numbers of people into smaller spaces. This requires additional research that studies the implication of integrating these urban giants in cities. 
Table 2. Sustainable Design Features and Iconicity.

\begin{tabular}{|c|c|c|c|c|c|c|c|c|c|c|c|}
\hline \multirow{2}{*}{\multicolumn{2}{|c|}{ Category }} & \multirow{2}{*}{ Aerodynamic Form } & \multirow{2}{*}{$\begin{array}{l}\text { Tripod-Like } \\
\text { Floor Plan }\end{array}$} & \multirow{2}{*}{ Diagrid System } & \multirow{2}{*}{$\begin{array}{c}\text { Vertical } \\
\text { Landscaping }\end{array}$} & \multirow{2}{*}{$\begin{array}{c}\text { "Vertical } \\
\text { Courtyard" or } \\
\text { Skydecks }\end{array}$} & \multirow{2}{*}{ Wind Turbine } & \multirow{2}{*}{ Exoskeleton } & \multirow{2}{*}{$\begin{array}{l}\text { Balconies and } \\
\text { Terraces }\end{array}$} & \multicolumn{2}{|c|}{ Shading Devices } \\
\hline & & & & & & & & & & Static & Dynamic \\
\hline 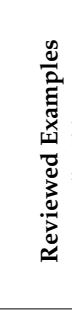 & & $\begin{array}{l}\text { Wuhan Greenland Center } \\
\text { Pearl River Tower } \\
\text { Oasia Hotel Downtown } \\
\text { Doha Tower } \\
\text { Iris Bay } \\
\text { 30 St Mary Axe Tower } \\
\text { Strata SE1 Tower } \\
\text { Post Office Tower } \\
\text { The Bow } \\
\text { KfW Headquarters } \\
\end{array}$ & $\begin{array}{l}\text { Wuhan } \\
\text { Greenland } \\
\text { Center } \\
\text { Devon Energy } \\
\text { Center }\end{array}$ & $\begin{array}{l}\text { Parkview Green } \\
\text { FangCaoDi } \\
\text { O-14 } \\
\text { The Bow } \\
\text { 30 St Mary Axe Tower }\end{array}$ & $\begin{array}{l}\text { Menara } \\
\text { Mesiniaga } \\
\text { ParkRoyal on } \\
\text { Pickering } \\
\text { CapitaGreen } \\
\text { Bosco Verticale } \\
\text { Oasia Hotel } \\
\text { Downtown }\end{array}$ & $\begin{array}{l}\text { Oasia } \\
\text { Downtown } \\
\text { National } \\
\text { Commercial } \\
\text { Bank } \\
\text { VIA 57 WEST } \\
\text { Torre Cube }\end{array}$ & $\begin{array}{l}\text { Pearl River } \\
\text { Tower } \\
\text { Bahrain } \\
\text { Towers } \\
\text { Strata SE1 } \\
\text { Tower }\end{array}$ & $\begin{array}{l}\text { Menara } \\
\text { Mesiniaga } \\
\text { Oasia Hotel } \\
\text { Downtown } \\
\text { O-14 }\end{array}$ & $\begin{array}{l}\text { Bosco Verticale } \\
\text { Aqua Tower } \\
\text { Beirut Terraces }\end{array}$ & $\begin{array}{l}\text { Menara Mesiniaga } \\
\text { Doha Tower } \\
\text { Iris Bay } \\
\text { KfW Headquarters } \\
\text { New York Times } \\
\text { Tower } \\
\text { Salesforce tower }\end{array}$ & $\begin{array}{l}\text { Al Bahar } \\
\text { Towers } \\
\text { GSW } \\
\text { Headquarters }\end{array}$ \\
\hline \multirow{2}{*}{ 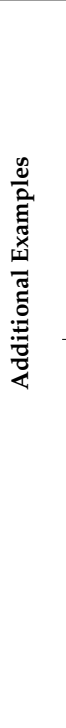 } & 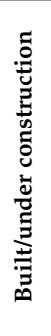 & $\begin{array}{l}\text { Guangzhou International } \\
\text { Finance Center } \\
\text { Absolute Towers } \\
\text { Al Dar Headquarters } \\
\text { Burj Khalifa } \\
\text { Jeddah Tower }\end{array}$ & $\begin{array}{l}\text { Burj Khalifa } \\
\text { Jeddah Tower }\end{array}$ & $\begin{array}{l}\text { Hearst Tower } \\
\text { Guangzhou } \\
\text { International Finance } \\
\text { Center } \\
\text { Poly International Plaza } \\
\text { Al Dar Headquarters } \\
\text { The Capital Gate } \\
\text { Building } \\
\text { Tornado Tower } \\
\text { NEO Bankside } \\
\text { D2 Tower }\end{array}$ & $\begin{array}{l}\text { The Met } \\
\text { Newton Suites } \\
\text { Antilia Tower } \\
\text { One Central } \\
\text { Park } \\
\text { ACROS } \\
\text { Fukuoka } \\
\text { Tao Zhu Yin } \\
\text { Yuan }\end{array}$ & The Interlace & $\begin{array}{l}\text { Indigo } \\
\text { Building } \\
\text { Aquarius } \\
\text { Tower }\end{array}$ & COR Tower & $\begin{array}{l}\text { The Wave } \\
\text { Absolute Towers } \\
\text { Regalia } \\
\text { Condominium } \\
\text { Tower } \\
\text { L'Arbre Blanc in } \\
\text { France } \\
\text { City Hyde Park } \\
\text { Marina City }\end{array}$ & $\begin{array}{l}\text { Price Tower } \\
\text { Solaris-Singapore } \\
\text { Science Centre }\end{array}$ & - \\
\hline & 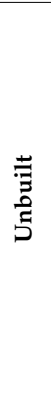 & Nakheel Tower & $\begin{array}{l}\text { The Mile High } \\
\text { Illinois }\end{array}$ & - & $\begin{array}{l}\text { La Tour des } \\
\text { Cèdres } \\
\text { Tokyo-Nara } \\
\text { Tower } \\
\text { EDITT Tower } \\
\text { Sky Village } \\
\text { New York } \\
\text { Tower } \\
\text { Vertical Park } \\
\text { Gwanggyo } \\
\text { Power Center } \\
\text { The Mile High } \\
\text { Eco-Skyscraper }\end{array}$ & - & $\begin{array}{l}\text { Anara Tower } \\
\text { Burjal-Taqa }\end{array}$ & - & $\begin{array}{l}\text { Solstice on the } \\
\text { ParkVancouver } \\
\text { Pair }\end{array}$ & - & $\begin{array}{l}\text { Cactus } \\
\text { Building }\end{array}$ \\
\hline
\end{tabular}




\section{Future Research}

This paper has focused on the sustainable design and iconicity nexus. Future research may address other important sustainability issues, such as social and economic. Many sustainable skyscrapers have claimed that their green features foster better social and public life. For example, Shanghai Tower has promised to make its wonderful skygardens accessible to the public. However, since its opening, the tower's gardens are accessible only to its tenants. Overall, these gardens are underused. In a similar fashion, 30 St Mary Axe in London has promised to make its airy, bright top floor accessible to the public; however, it failed to do so. Although the public has access to the spacious base of the tower, this exquisite experience at the top is exclusive for tenants and their invitees. At the ground floor, the tower has an efficient footprint, maximizing the public space and natural lighting of the ground level. Much of the surrounding site has been paved to form a spacious pedestrian plaza (the size of eight tennis courts), which contains a café, tables, and chairs. However, this spacious, airy plaza lacks protection from the elements and it is underused. Importantly, future research may examine design and "sustainable behavior" nexus of tall buildings. In his 2011 book titled Fostering Sustainable Behavior: An Introduction to Community-Based Social Marketing, Doug McKenzie-Mohr elucidates that people often do not behave "sustainably" [43]. Therefore, if sound design and planning aim to promote sustainable buildings, it is important that people adopt "sustainable" lifestyle that reduces consumption of resources, carbon emission, and waste, and reuses and recycles materials [44].

Further, future research may examine the economic, performance, and efficiency of "sustainable" tall buildings. For example, Bank of America (BoA) Tower integrates a host of high-tech sustainable features including an on-site cogeneration plant that works in concert with an ice storage system to reduce the building's peak energy demands. It collects and recycles rainwater captured on the building's roof. Low-flow fixtures, dual flush toilets, and waterless urinals further reduce water use. A sub-level graywater treatment plant provides water for the building's cooling tower. BoA Tower was initially praised for being the "world's most sustainable skyscraper", and it received LEED Platinum certification, the USGBC's highest rating. However, the 56-story building was recently critiqued for its high-energy consumption. According to data released by New York City (NYC) in the fall of 2012, the Bank of America Tower produced more greenhouse gases and used more energy per square foot than any other comparably sized office building in Manhattan [35].

Funding: This project received no funding.

Acknowledgments: The author would like to thank the journal's reviewers for feedback and staff for processing the paper. All the photographs and sketches of this paper are by the author except that of Beirut Terraces by Omran Al-Kodmany.

Conflicts of Interest: The author declares no conflict of interest.

\section{References}

1. The United Nations. World Population Prospects: The 2015 Revision; The United Nations: New York, NY, USA, 2015.

2. Zolli, A. Learning to bounce back. The New York Times, 2 November 2012. Available online: http: / /www.nytimes.com/2012/11/03/opinion/forget-sustainability-its-about-resilience.html (accessed on 15 July 2017).

3. Godschalk, D.R.; Rouse, D.C. Sustaining Places: Best Practices for Comprehensive Plans; PAS Report 578; American Planning Association: Chicago, IL, USA, 2015. Available online: https:/ /www.planning.org/ publications/report/9026901/ (accessed on 15 July 2017).

4. UN HABITAT. Available online: https://unhabitat.org/wuf/ (accessed on 15 July 2017).

5. World Commission on Environment and Development (WCED). Our Common Future; Oxford University Press: Oxford, UK, 1987.

6. Merriam-Webster. Available online: https://www.merriam-webster.com/dictionary/sustainable (accessed on 15 July 2017). 
7. HEC Global Learning. What Is Sustainability? Available online: http://www.globalfootprints.org/ sustainability (accessed on 15 July 2017).

8. Pruetz, R. Lasting Value: Open Space Planning and Preservation Successes; Routledge: London, UK, 2017; pp. 32-38.

9. Krier, L. The Architecture of Community; Island Press: Washington, DC, USA, 2009.

10. Beatley, T. Vertical city in a garden. In Planning; American Planning Association: Chicago, IL, USA, 2016; pp. 64-69.

11. Owen, D. Green Metropolis: Why Living Smaller, Living Closer, and Driving Less Are the Keys to Sustainability; Penguin Group: New York, NY, USA, 2009.

12. CTBUH. Available online: http://www.ctbuh.org/ (accessed on 15 July 2018).

13. Emporis. Available online: https:/ / www.emporis.com/ (accessed on 15 July 2018).

14. Al-Kodmany, K. The Vertical City: A Sustainable Development Model; WIT Press: Southampton, UK, 2018.

15. Al-Kodmany, K. Eco-Towers: Sustainable Cities in the Sky; WIT Press: Southampton, UK, 2015.

16. Al-Kodmany, K.; Ali, M. The Future of the City: Tall Buildings and Urban Design; WIT Press: Southampton, UK, 2013.

17. Gang, J. Wanted: Tall buildings less iconic, more specific. In Proceedings of the CTBUH 8th World Congress on Tall \& Green: Typology for a Sustainable Urban Future, Dubai, UAE, 3-5 March 2008; pp. 496-502.

18. Iffrig, A. Iconic Architecture Redefined: Classical Architectural Features versus Signature Architecture Design. Suite101.com. 25 June 2008. Available online: http://architecture.suite101.com/ (accessed on 15 July 2018).

19. Sisson, P. Tower as Trellis: A Plant-Covered High-Rise Reimagines Tropical Buildings. Curbed, Architecture, 16 May 2016. Available online: https://www.curbed.com/2016/5/16/11682304/tropical-skyscrapersingapore-woha-oasia (accessed on 15 July 2017).

20. Lee, E. O-14 Green Dubai Tower. Inhabitat, 30 January 2007. Available online: http:/ /inhabitat.com/ o-14dubai-commercial-tower/ (accessed on 15 July 2017).

21. Pham, D. Bosco Verticale: The World's First Vertical Forest Nears Completion in Milan. Inhabitat, 24 January 2013. Available online: http:/ / inhabitat.com/bosco-verticale-the-worlds-first-vertical-forestnears-completion-in-milan-new-photos/ (accessed on 15 July 2017).

22. Holmes, J.D. Wind Loading of Structure; Spon Press: London, UK, 2001.

23. Baker, W. The world's tallest building-Burj Dubai, UAE. In Proceedings of the International Conference on Tall Buildings, Seoul, Korea, 10-13 October 2004; pp. 1168-1169.

24. Isyumov, N.; Fediw, A.; Colaco, J.; Banavalkar, P.V. Performance of a tall building under wind excitation. J. Wind Eng. Ind. Aerodyn. 1992, 41-44, 1053-1064. [CrossRef]

25. Hayashida, H.; Iwasa, Y. Aerodynamic shape effects of tall building for vortex induced Vibration. J. Wind Eng. Ind. Aerodyn. 1990, 33, 237-242. [CrossRef]

26. Dutton, R.; Isyumov, N. Reduction of tall building motion by aerodynamic treatments. J. Wind Eng. Ind. Aerodyn. 1990, 36, 739-747. [CrossRef]

27. Sarkisian, M. Designing Tall Buildings Structure as Architecture; Routledge, Taylor and Francis Group: London, UK; New York, NY, USA, 2012.

28. Terranova, A. The Great Skyscrapers of the World; White Star: Vercelli, Italy, 2003.

29. Beedle, L.; Ali, M.; Armstrong, P. Skyscraper and the City: Design, Technology, and Innovation; Edwin Mellen Press: Lewiston, NY, USA, 2007.

30. Goncalves, J.C.S. The Environmental Performance of Tall Buildings; Earth Scan: London, UK, 2010.

31. Wood, A. Green or Grey? The Aesthetics of Tall Building Sustainability. In Proceedings of the CTBUH 8th World Congress, Dubai, UAE, 3-5 March 2008.

32. Gissen, D. Big \& Green; Princeton Architectural Press: New York, NY, USA, 2002.

33. Yeang, K.; Powell, R. Designing the ecoskyscraper: Premises for tall building design. Struct. Des. Tall Spec. Build. 2007, 16, 411-427. [CrossRef]

34. Despommir, D.; Ellington, E. The vertical farm: The sky-scraper as vehicle for a sustainable urban agriculture. In Proceedings of the CTBUH 8th World Congress on Tall \& Green: Typology for a Sustainable Urban Future, Dubai, UAE, 3-5 March 2008; pp. 311-318. 
35. Koolhaas, R. Rem Koolhaas's Venice Biennale Will “Be about Architecture, Not Architects”. Architecture and Design Blog, Rem Koolhaas. Available online: https:/ / www.theguardian.com/artanddesign/architecturedesign-blog/2014/mar/12/rem-koolhaas-venice-biennale-architecture (accessed on 15 July 2018).

36. DeWolf, C. How Architects Are Changing High-Rise Living with Amazing Balconies That Stand out in More Ways than One. Architecture and Design, 1 February 2018. Available online: https:/ / www.scmp.com/lifestyle/ article/2131347/how-architects-are-changing-high-rise-living-amazing-balconies-stand-out (accessed on 15 July 2018).

37. Stott, R. Folsom Tower/Studio Gang. ArchDaily, 11 July 2014. Available online: https://www.archdaily. com/526702/studio-gang-architects-reveals-design-of-twisting-san-francisco-skyscraper (accessed on 15 July 2018).

38. Xie, J. Jeanne Gang's Plan for Miami is a Choppy, Prismatic Tower. Curbed, 24 October 2014. Available online: https:/ / www.curbed.com/2014/10/24/10031858/jeanne-gang-studio-miami-new-building (accessed on 15 July 2018).

39. Lomholt, I. Regalia Condominium Tower. E-Architect, 9 January 2018. Available online: https://www.earchitect.co.uk/miami/regalia-condominium-tower (accessed on 15 July 2018).

40. Mouzon, S. Sustainability: What Are The Key Tenets of the Original Green Movement? Qura. January 2011. Available online: https:/ / www.quora.com/Sustainability-What-are-the-key-tenets-of-the-Original-Greenmovement (accessed on 1 August 2018).

41. Mouzon, S. The Original Green: Unlocking The Mystery of True Sustainability; Guild Foundation Press: Los Angeles, CA, USA, 2011.

42. Alter, L. The Original Green by Steve [Stephen] Mouzon: A Must-Read If You Care about Sustainable Design. Treehugger, 31 May 2010. Available online: https:/ / www.treehugger.com/culture/the-original-green-bysteve-mouzon-a-must-read-if-you-care-about-sustainable-design.html (accessed on 15 June 2018).

43. McKenzie-Mohr, D. Fostering Sustainable Behavior: An Introduction to Community-Based Social Marketing; New Society Publishers: Gabriola Island, BC, Canada, 2011.

44. Johnson, T. Roadmap on the Future Research Needs of Tall Buildings; Oldfield, P., Trabucco, D., Wood, A., Eds.; Council on Tall Buildings and Urban Habitat: Chicago, IL, USA, 2014; pp. 1-103. Available online: http:/ / www.ctbuh.org/roadmap/ResearchRoadmap_CTBUH-CIB-UNESCO.pdf (accessed on 15 July 2018).

(C) 2018 by the author. Licensee MDPI, Basel, Switzerland. This article is an open access article distributed under the terms and conditions of the Creative Commons Attribution (CC BY) license (http:/ / creativecommons.org/licenses/by/4.0/). 